\title{
Synthesis of novel tetravalent galactosylated DTPA-DSPE and study on hepatocyte-targeting efficiency in vitro and in vivo
}

This article was published in the following Dove Press journal:

International Journal of Nanomedicine

10 August 2013

Number of times this article has been viewed

Yan Xiao

Huafang Zhang

Zhaoguo Zhang

Mina Yan

Ming Lei

Ke Zeng

Chunshun Zhao

School of Pharmaceutical Sciences, Sun Yat-Sen University, Guangzhou, People's Republic of China
Correspondence: Chunshun Zhao School of Pharmaceutical Sciences, Sun Yat-Sen University, 132 Waihuan East Road, Guangzhou 510006,

People's Republic of China

Tel +862039943।I8

$\mathrm{Fax}+862039943118$

Email zhaocs@mail.sysu.edu.cn

\begin{abstract}
For the purposes of obtaining a hepatocyte-selective drug delivery system, a novel tetravalent galactosylated diethylenetriaminepentaacetic acid-distearoyl phosphatidylethanolamine (4Gal-DTPA-DSPE) was synthesized. The chemical structure of 4Gal-DTPA-DSPE was confirmed by proton nuclear magnetic resonance and mass spectrometry. The four galactose-modified liposomes (4Gal-liposomes) were prepared by thin-film hydration method, then doxorubicin (DOX) was encapsulated into liposomes using an ammonium sulfate gradient loading method. The liposomal formulations with 4Gal-DTPA-DSPE were characterized by laser confocal scanning microscopy and flow cytometry analysis, and the results demonstrated that the 4Gal-liposomes facilitated the intracellular uptake of DOX into HepG2 cells via asialoglycoprotein receptor-mediated endocytosis. Cytotoxicity assay showed that the cell proliferation inhibition effect of $4 \mathrm{Gal}$-liposomes was higher than that of the conventional liposomes without the galactose. Additionally, pharmacokinetic experiments in rats revealed that the $4 \mathrm{Gal}$-liposomes displayed slower clearance from the systemic circulation compared with conventional liposomes. The organ distributions in mice and the study on frozen sections of liver implied that the 4Gal-liposomes enhanced the intracellular uptake of DOX into hepatocytes and prolonged the circulation. Taken together, these results indicate that liposomes containing 4Gal-DTPA-DSPE have great potential as drug delivery carriers for hepatocyte-selective targeting.
\end{abstract}

Keywords: targeted drug delivery, liposomes, pharmacokinetics, galactose, ASGP-R, doxorubicin

\section{Introduction}

Liver diseases, including virus infections, liver cirrhosis, and hepatocellular carcinoma, have become a significant health challenge around the world, due to the lack of curative treatment options besides liver resections and transplantation. ${ }^{1}$

Hepatocytes, the liver parenchymal cells, constitute $60 \%-80 \%$ of the mass of the liver tissue, and liver diseases mainly develop from the hepatocytes. ${ }^{2}$ Although hepatocytes are the main functional cells of the liver, high uptake of compounds into other liver cell types, such as Kupffer cells, often leads to serious degradation of them, ${ }^{3}$ which in some cases destroys their therapeutic activity. However, hepatocyte targeting is often equated with liver targeting, and total liver uptake of a compound is measured without proper identification of the cell type. This has induced the necessity of the development of cell-specific delivery carriers, through surface modification, which are usually transferred via a receptor-mediated endocytosis system. Asialoglycoprotein receptors (ASGP-Rs) are exclusively expressed on the membranes of hepatocytes, providing active membrane-bound sites, and have been used as the target receptors for drug 
delivery to the hepatocytes. ${ }^{4,5}$ ASGP-Rs contain $1-5 \times 10^{5}$ binding sites per cell, and their main function is to recognize, bind, and internalize ASGPs that contain terminal galactose (Gal) or N-acetylgalactosamine (GalNAc) residues., ${ }^{6,7}$

Many studies have proved that both natural and synthetic carbohydrates can establish the structure-affinity relationship for the ASGP-R. Baenziger and Maynard ${ }^{8}$ and Baenziger and Fiete $^{9}$ have shown that the human receptor exhibits specificity for terminal Gal and GalNAc on desialylated glycoproteins. Lee et $a 1^{10}$ have also demonstrated that the affinity and specificity of the ASGP-R is a consequence of oligovalent interactions with its physiological ligands, a process termed "cluster glycoside effect." Synthetic oligosaccharides tested on rabbit hepatocytes by Lee et al further strengthened the binding hierarchy of polyvalent ligands: tetra-antennary $>$ triantennary $>>$ biantennary $>>$ monoantennary as a cluster glycoside effect.

Hepatocyte-selective targeting can be achieved through introduction of cells recognizing ligands on the liposomal surface. As many studies have proved that Gal-modified liposomes can be recognized by the ASGP-R on the liver parenchymal cells and incorporated into the cells by endocytosis, Gal was used as a liver-targeting moiety. Many studies have verified that liposomes modified with galactosylated lipid achieves effective targets to hepatocytes. ${ }^{11-14}$ Moreover, the half maximal inhibitory concentration values for mono-, bi-, tri-, and tetra-antennary oligosaccharides were found to be approximately $1 \times 10^{-3}, 1 \times 10^{-6}, 5 \times 10^{-9}$, and $10^{-9} \mathrm{M}$, respectively. In other words, although the number of Gal residues/mol of ligand increased only four-fold, the inhibitory potency increased 1,000,000-fold..$^{15}$

Most studies have focused on cholesterol (Chol) as a lipophilic anchor moiety, because galactosylated Chol derivatives can be easily synthesized, where Chol and Gal ligands are linked by an ether bond. ${ }^{16}$ However, it is very easy for Chol to fall out from the liposome membrane if the hydrophilic head group is too large, whereas distearoylphosphatidylethanolamine (DSPE) anchor may be located deeper in the liposome membrane with its two long aliphatic chains $\left(2 \times 17-\mathrm{CH}_{2}-\right)$, thus steadily inserting into the walls of lipid bilayer structures. ${ }^{17,18}$ In addition, Yeagle ${ }^{19}$ reported that red cell membrane sodium-potassium adenosine triphosphatase activity gradually decreased with elevated Chol levels. Furthermore, the proportion of Chol in the cell membrane limited the amount of Chol in liposomes, ${ }^{20}$ thus limiting the quantity of ligands in liposomes. In contrast, DSPE is a natural body component with good biocompatibility, and the maximum amount of phospholipid in liposomes can reach $80 \%{ }^{21}$
Therefore, the quantity of ligands in liposome can be greatly increased when DSPE serves as a lipophilic anchor moiety. Hence, DSPE was employed to connect Gal ligands in our study. Although multivalent Gal ligands have been previously reported, ${ }^{22}$ few articles describe ligands beyond three Gal units. As we mentioned, targeting efficiency increases from monoantennary to tetra-antennary as a cluster glycoside effect. Therefore, in our study, four Gals were firstly connected to a DSPE simultaneously to improve the targeting efficiency.

In the present study, we designed and synthesized a novel multifunctional liposomal material, tetravalent galactosylated diethylenetriaminepentaacetic acid-distearoylphosphatidylethanolamine (4Gal-DTPA-DSPE), containing (1) a lipophilic anchor moiety (DSPE) for stable incorporation into liposomes, (2) a DTPA for connection of DSPE and ligands, and (3) four Gal moieties for the cell surface receptors in hepatocytes.

Doxorubicin (DOX) was selected as a model drug, as it can be efficiently encapsulated in liposomes via transmembrane sulfate ammonium gradients and form a stable drug-sulfate gel in the liposome interior, which results in a greater stability of DOX liposomes in plasma and during storage. Additionally, DOX is a cancer chemotherapeutic agent, and its fluorescence allows it to be identified within tissues and cells.

This study aimed to develop a Gal-modified liposomal formulation for DOX delivery and evaluate its effect of targeting to the liver. 4Gal-liposomes were composed of 1,2-distearoyl-sn-glycero-3-phosphocholine (DSPC), Chol, and 4Gal-DTPA-DSPE. To evaluate the liver-targeting delivery property of 4Gal-liposomes, in vitro cellular uptake of DOXloaded 4Gal-liposomes was visualized by confocal scanning microscopy and measured by flow cytometry. The cytotoxicity study was conducted to evaluate the safety of 4Gal-liposomes by 3-(4,5-Dimethylthiazol-2-yl)-2,5-diphenyltetrazolium bromide (MTT) assay. Furthermore, pharmacokinetics of 4Galliposomes studied in rat and tissue distribution was carried out by in vivo imaging. Finally, the analysis of frozen sections of liver was carried out in order to study the mechanism of the targeting ability of 4Gal-liposomes to liver tissue.

The results suggest that the compound described in this work could serve as a valuable tool for studying hepatic endocytosis, and is a suitable carrier for site-specific drug delivery to the liver.

\section{Materials and methods Materials}

DTPA was purchased from Aladdin Chemistry Co Ltd (Shanghai, People's Republic of China). DSPE and DSPC 
were purchased from Genzyme Corporation (Cambridge, MA, USA). Anhydrous pyridine was purchased from Sigma Chemical Co (St Louis, MO, USA). 2,3,4,6-TetraO-acetyl- $\beta$-D-galactopyranosyl bromide was purchased from J\&K Scientific Co Ltd (Shanghai, People's Republic of China). HepG2 cells and Hela cells were purchased from the Laboratory Animal Center of Sun Yat-sen University (Guangzhou, People's Republic of China). Cells were cultured in Dulbecco's Modified Eagle's medium supplemented with $10 \%$ fetal bovine serum and antibiotics (streptomycin $100 \mathrm{U} / \mathrm{mL}$, penicillin $100 \mathrm{U} / \mathrm{mL}$ ) at $37^{\circ} \mathrm{C}$ in humidified air with $2 \%$ carbon dioxide. All other chemicals were of reagent grade.

\section{Experimental animals}

Male Kunming mice (18-20 g) and male Sprague Dawley rats (220-250 g) were purchased from the Laboratory Animal Center of Sun Yat-sen University. All experimental procedures were approved and supervised by the Institutional Animal Care and Use Committee of Sun Yat-sen University.

\section{Synthesis of 4Gal-DTPA-DSPE conjugates}

4Gal-DTPA-DSPE was synthesized by the following procedure (shown in Figure 1): (1) activation of DTPA, (2) connection of DTPA and DSPE, (3) galactosylation of DTPA-DSPE, and (4) removal of protection from hydroxyl groups. In the synthetic process, the carboxyl groups of DTPA were firstly

1
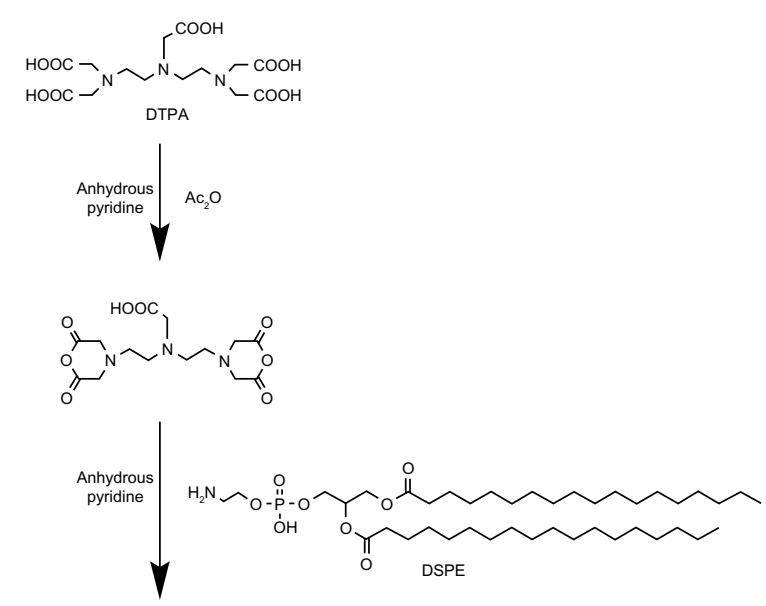

2
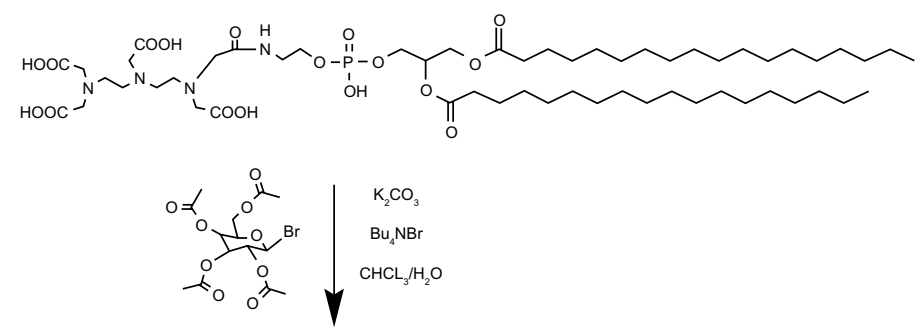

3
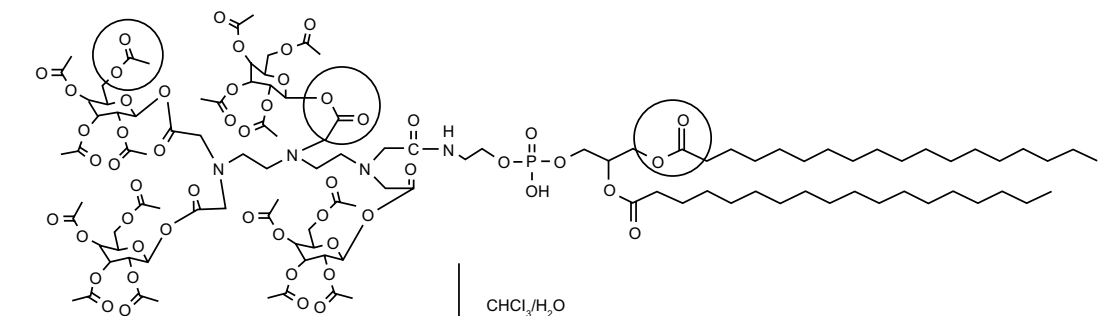
$\mathrm{CHCl}_{3} \mathrm{H}_{2} \mathrm{O}$

$\mathrm{NH}_{3}$

4

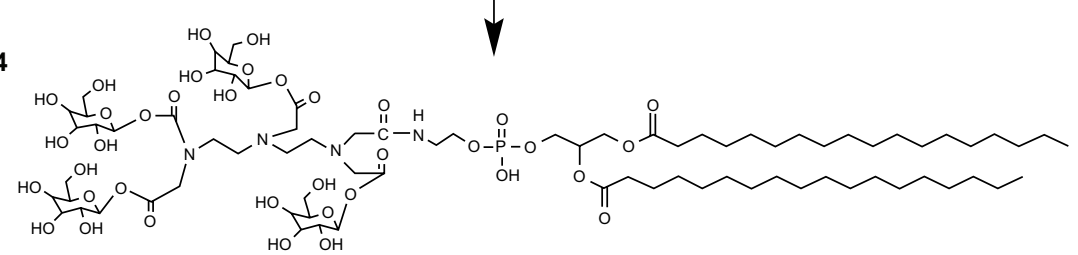

Figure I The synthetic routes of tetravalent galactosylated diethylenetriaminepentaacetic acid-distearoylphosphatidylethanolamine (4Gal-DTPA-DSPE) conjugates. 
activated by the acetic anhydride dissolved in anhydrous pyridine. ${ }^{23}$ Then the amino group of DSPE was covalently linked to a carboxyl group of DTPA ${ }^{17}$ The next step was to connect the remaining carboxyl groups of DTPA and 1-hydroxyl group of Gals (other hydroxyl groups were protected by acetylation). ${ }^{24}$ Finally, the protecting groups of hydroxyl groups were removed selectively. ${ }^{25}$ The detailed synthetic routes of the compound are depicted in Supplementary material. The structure of 4Gal-DTPA-DSPE and intermediate products was characterized by ${ }^{1} \mathrm{H}-\mathrm{NMR}$ ( ${ }^{1} \mathrm{H}-\mathrm{Nuclear}$ Magnetic Resonance) and mass spectrometry (Figures S1-S4).

\section{Preparation and characterization of liposomes}

DSPC, Chol, and 4Gal-DTPA-DSPE (molar ratio is shown in Table 1) were dissolved in $\mathrm{CHCl}_{3}$ and dried under an $\mathrm{N}_{2}$ stream. A trace amount of $\mathrm{CHCl}_{3}$ was removed by keeping the lipid film under a vacuum. The lipid film was hydrated with $250 \mathrm{mM}\left(\mathrm{NH}_{4}\right)_{2} \mathrm{SO}_{4}$ to obtain a blank liposome suspension. The liposome suspension was then sequentially extruded through polycarbonate membranes (Avanti ${ }^{\circledR}$ Mini-Extruder; Avanti Polar Lipids, Inc, Alabaster, AL, USA) with a pore size of $200 \mathrm{~nm}$ and $100 \mathrm{~nm}$. The resulting liposomes were dialyzed (molecular weight cutoff size 14,000) against phosphatebuffered saline (PBS) ( $\mathrm{pH} \mathrm{7.4)}$ at $37^{\circ} \mathrm{C}$. For drug loading, DOX was dissolved in a small volume of deionized water and added to the liposomes to achieve a drug:lipid ratio of 1:10 (mol/mol). The loading process was carried out at $65^{\circ} \mathrm{C}$ for 30 - minutes, and DOX liposomes were obtained. The particle size and zeta potential of the DOX liposomes were analyzed using a Malvern Zetasizer Nano ZS90 (Malvern Instruments Ltd, Malvern, UK). DOX-loaded 4Gal-liposomes were stained with phosphotungstic acid and observed by transmission electron microscopy (FEI Tecnai G2 F30, FEI company, Hillsboro, OR, USA). To determine the encapsulation efficiency (EE), unencapsulated DOX was separated from liposomes by size exclusion chromatography using a Sephadex G-50 column (Pharmacia Company, Uppsala, Sweden). PBS (pH 7.4) was used as the eluent. The eluted liposomes were collected and lysed with Triton X-100 (1\%, v/v). The DOX concentration was determined by ultraviolet spectrophotometry (233 nm). The EE of DOX was calculated based on the ratio of liposomal drug to total drug.

\section{Cellular internalization}

\section{Confocal laser scanning microscopy}

HepG2 cells and Hela cells were used for the cell internalization study. HepG2 cells expressing ASGP-Rs were derived from a human hepatocellular carcinoma. Hela cells without ASGP-Rs served as the control. ${ }^{26-32}$ Cells were seeded on a cover glass in a 24 -well culture plate at a density of $7 \times 10^{4}$ cells per well. The cells were incubated for 24 hours to $50 \%$ confluence and then treated with free DOX and a variety of liposomal DOX formulations for 2 hours. All groups were given a DOX equivalent dose of $30 \mu \mathrm{g} / \mathrm{mL}$. The cells were washed three times with cold PBS, fixed with 4\% paraformaldehyde at room temperature, and permeabilized with $0.5 \%$ Triton $\mathrm{X}-100$ in PBS. The cells were stained with 4',6-diamidino-2phenylindole (DAPI) $(1 \mu \mathrm{g} / \mathrm{mL})$ in order to visualize the nuclei. A Zeiss LSM710 laser scanning confocal microscope (Carl Zeiss Meditec AG, Jena, Germany) was used to investigate the intracellular uptake and subcellular distribution of DOX (excitation/emission wavelength: $488 \mathrm{~nm} / 560 \mathrm{~nm}$ ).

\section{Flow cytometry analysis}

Cell suspension $\left(8 \times 10^{5}\right.$ cells/well $)$ was seeded in a 24 -well culture plate and incubated for 24 hours until $80 \%$ confluence. The cells were then treated with free DOX and a variety of liposomal DOX formulations for 2 hours. All groups were given a DOX equivalent dose of $30 \mu \mathrm{g} / \mathrm{mL}$. The cells were harvested and washed three times with cold PBS. The drugfree cells served as a reference sample. The cellular uptake of DOX was measured by using a flow cytometer EPICS XL (Beckman Coulter, Inc, Fullerton, CA, USA). The intracellular DOX was excited with an argon laser at a wavelength of $488 \mathrm{~nm}$, and the fluorescence was detected at $575 \mathrm{~nm}$. Data were analyzed with FlowJo software (Tree Star, Inc, Ashland, OR, USA).

Table I Composition and physicochemical properties of the prepared liposomes

\begin{tabular}{llllll}
\hline DOX-liposomes & $\begin{array}{l}\text { Molar ratio (DSPCI } \\
\text { Chol/4Gal-DTPA-DSPE) }\end{array}$ & $\begin{array}{l}\text { Particle } \\
\text { size (nm) }\end{array}$ & PDI & $\begin{array}{l}\text { Zeta } \\
\text { potential }(\mathbf{m V})\end{array}$ \\
\hline Conventional liposomes & $55: 45: 0$ & $159.1 \pm 1.3$ & $0.083 \pm 0.060$ & $-22.5 \pm 2.3$ & $94.6 \pm 5.8$ \\
4Gal-liposomes (5\%) & $50: 45: 5$ & $168.8 \pm 2.6$ & $0.079 \pm 0.038$ & $-28.1 \pm 1.6$ & $92.7 \pm 7.2$ \\
4Gal-liposomes (10\%) & $50: 40: 10$ & $164.4 \pm 1.5$ & $0.084 \pm 0.027$ & $-33.2 \pm 3.5$ & $90.4 \pm 4.9$ \\
\hline
\end{tabular}

Note: (Mean $\pm \mathrm{SD}, \mathrm{n}=3$ ).

Abbreviations: Chol, cholesterol; DOX, doxorubicin; DSPC, I,2-distearoyl-sn-glycero-3-phosphocholine; 4Gal-DTPA-DSPE, tetravalent galactosylated diethylenetriaminepentaacetic acid-distearoyl phosphatidylethanolamine; PDI, polydispersity index; EE, encapsulation efficiency. 


\section{Competition assay}

Free Gal was used as a competitive inhibitor to study whether the cellular uptake of the 4Gal-liposomes was via ASGP-Rs. HepG2 cells and Hela cells were seeded in 24-well plates at a density of $7 \times 10^{4}$ cells (in $500 \mu \mathrm{L}$ culture media) per well and incubated for 24 hours until $50 \%$ confluence, to which $200 \mu \mathrm{L}$ of Gal solution $(100 \mathrm{mM})$ was added, and then $37 \mu \mathrm{L}$ of $4 \mathrm{Gal}-$ liposomes (DOX concentration of $600 \mu \mathrm{g} / \mathrm{mL}$ ) was added to incubate for 2 hours. The total volume of culture media was approximately $700 \mu \mathrm{L}$. The treatment samples were the same as those in "Confocal laser scanning microscopy."

\section{Cell cytotoxicity assay}

The cytotoxicity of free DOX and various liposomes (conventional liposomes, 4Gal-liposomes, and blank 4Gal-liposomes) on HepG2 cells and Hela cells was examined via MTT assay. Briefly, cells were seeded in 96-well plates at a density of $1 \times 10^{4}$ cells per well and incubated for 24 hours. Then the cells were treated with serial concentrations of free DOX or a variety of liposomal DOX formulations. The drug-free cells served as a reference sample, and the cell-free culture medium served as a blank control. After 24 hours incubation, $10 \mu \mathrm{L}$ of MTT solution $(5 \mathrm{mg} / \mathrm{mL})$ was added to each well and incubated for a further 4 hours. Finally, the medium was replaced with $150 \mu \mathrm{L}$ dimethyl sulfoxide (DMSO), and the optical density (OD) was determined with a microplate reader at a wavelength of $570 \mathrm{~nm}$ in triplicate. Relative inhibition was calculated by the following formula. Experiments were repeated three times, and data were presented as mean \pm standard deviation.

$$
\text { Relative viability }=\frac{\text { OD reference }- \text { OD blank }}{\text { OD sample }- \text { OD blank }}
$$

Relative inhibition $=1-$ relative viability .

\section{Pharmacokinetic studies in rats}

To obtain preliminary parameters about the pharmacokinetic properties of the $4 \mathrm{Gal}$-liposomes, 15 Sprague Dawley rats were divided into three groups at random and treated with free DOX, conventional liposomes, and 4Gal-liposomes (10\%), respectively. All groups were given a DOX equivalent dose of $10 \mathrm{mg} / \mathrm{kg}$, and blood samples were collected at 10 minutes, 30 minutes, 1 hour, 2 hours, 4 hours, 6 hours, and 8 hours after drug administration from the jugular vein. Then the plasma was obtained by centrifuging immediately at 5,000 rpm for 10 minutes. A total of $20 \mu \mathrm{L}$ of internal standard (salicylic acid, $10.4 \mu \mathrm{g} / \mathrm{mL}$ in methanol) was added to $100 \mu \mathrm{L}$ of plasma and mixed for 30 seconds. After adding $25 \mu \mathrm{L}$ of perchloric acid $(17.5 \%, \mathrm{v} / \mathrm{v})$ and eddying for 1 minute, the plasma samples were centrifuged at $13,000 \mathrm{rpm}$ for 10 minutes. Then an aliquot of $20 \mu \mathrm{L}$ of the supernatant solution was injected into the high performance liquid chromatograph (HPLC) (Hitachi, Tokyo, Japan). Samples were separated by Luna-C18 column $(150 \times 4.6 \mathrm{~mm}, 5 \mu \mathrm{m}$; Phenomenex, Torrance, $\mathrm{CA}$, USA). The mobile phase consisting of $\mathrm{NH}_{4} \mathrm{H}_{2} \mathrm{PO}_{4}$ $(0.01 \mathrm{~mol} / \mathrm{L})$-acetonitrile-acetic acid $(76: 24: 0.4, \mathrm{v} / \mathrm{v} / \mathrm{v})$ was pumped at a flow rate of $1.0 \mathrm{~mL} / \mathrm{min}$. The column eluent was monitored at $233 \mathrm{~nm}$ at $40^{\circ} \mathrm{C}$.

\section{In vivo biodistribution study}

For the purpose of investigating the targeting ability of 4Gal-liposomes to liver, Kunming mice received a single intravenous injection of free DOX and a variety of DOX liposomes at a DOX equivalent dose of $5 \mathrm{mg} / \mathrm{kg}$. At 3 hours postadministration, the mice were sacrificed and major organs such as hearts, livers, spleens, lungs, and kidneys were excised. The distribution of DOX (excitation/emission wavelength: $488 \mathrm{~nm} / 560 \mathrm{~nm}$ ) was detected using an in vivo imaging system (Night OWL II LB983; Berthold Technologies $\mathrm{GmbH}$ and Co KG, Bad Wildbad, Germany).

\section{Study on frozen sections of liver}

Free DOX and a variety of liposomal DOX formulations were injected intravenously into the tail vein of the mice at a DOX equivalent dose of $5 \mathrm{mg} / \mathrm{kg}$. Mice were sacrificed at 3 hours postinjection. The liver was excised and frozen rapidly in dry ice, allowing the generation of $10 \mu \mathrm{m}$-thick cryosections. The tissue sections were fixed in cold acetone for 10 minutes, washed with PBS, blocked with bovine serum albumin for 1 hour, stained with fluorescein isothiocyanate-phalloidin (Sigma Chemical Co), and mounted with the DAPI-containing medium (VECTASHIELD ${ }^{\circledR}$ with DAPI; Vector Laboratories, Inc, Burlingame, CA, USA). Images were captured using a Zeiss LSM710 laser scanning confocal microscope.

\section{Statistical analysis}

Pharmacokinetic analysis was carried out by a twocompartment model method using the 3P97 practical pharmacokinetic program (edited by The Chinese Society of Mathematical Pharmacology New Edition 1997.11). Data were expressed as mean \pm standard deviation, and the statistical differences between the groups were determined by one-way analysis of variance using SPSS 13.0 software (IBM Corporation, Armonk, NY, USA). Data were considered significantly different at the level of $P<0.05$ and very significantly different at the level of $P<0.01$. 


\section{Results}

\section{Preparation and characteristics of liposomes}

The characterization results of liposomes are listed in Table 1, and the transmission electron microscopy image of 4Galliposomes is shown in Figure 2. The liposomes had a mean diameter of approximately $160 \mathrm{~nm}$ and relatively narrow distribution. The liposomes with or without Gal modification showed similar vesicle sizes, polydispersity indexes, and zeta potentials, indicating that the incorporation of 4Gal-DTPADSPE into lipid membrane had no influence on the physical properties of liposomes. DOX proved to be an excellent tool compound for target validation studies of liposomes. It could be conveniently encapsulated into liposomes at high concentration. EE of DOX into liposomes was $>90 \%$ at a drug:lipid ratio of 1:10.

\section{Cellular internalization}

The results of cellular uptake were displayed qualitatively by confocal images and quantitatively by flow cytometry analysis (shown in Figures 3 and 4). Strong DOX fluorescence intensity was observed in the nuclei of HepG2 cells treated with Gal-modified liposomes (Figure 3D1 and E1), which indicated that $4 \mathrm{Gal}$-liposomes were internalized more efficiently by HepG2 cells than conventional liposomes (Figure 3C1). Figure 3F1 shows that the uptake could be blocked by $100 \mathrm{mM}$ free Gal, indicating that Gal-modified liposomes were internalized by HepG2 cells via the ASGP-R, which was frequently expressed on the surface of hepatocytes. Similarly, flow cytometry results showed that the cellular uptake of Gal-modified liposomes was higher than that of unmodified liposomes and could be blocked by free Gal (shown in Figure 4A).

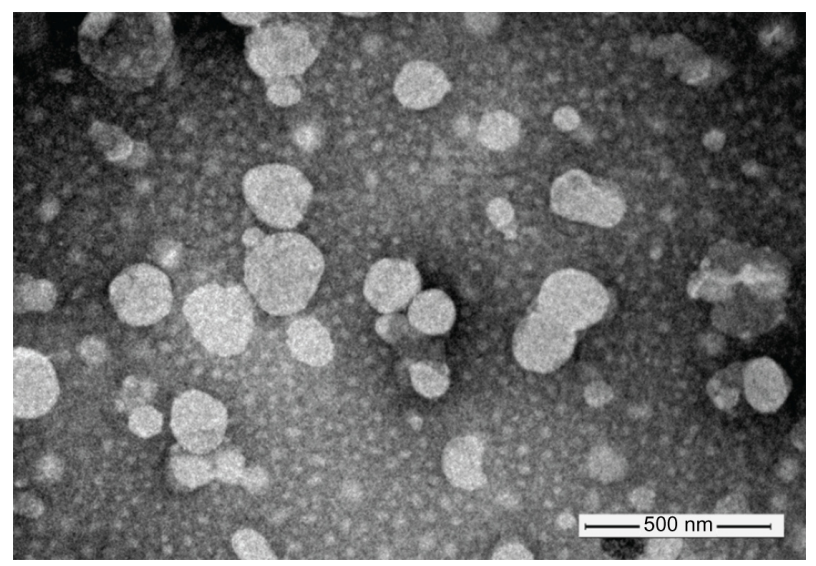

Figure 2 Negative stain (phosphotungstic acid) transmission electron microscopy image of four galactose-modified liposomes.
Hela cells, which lack ASGP-Rs, were selected to investigate whether the cellular uptake of Gal-modified liposomes was via the ASGP-R interaction. Figure 3D2 and E2 show that Gal-modified liposomes had a minor tendency to be internalized by Hela cells, and there was no significant difference between conventional liposomes (Figure 3C2) and Gal-modified liposomes. The fluorescence intensity of Gal-modified liposomes in Hela cells was weaker than that in HepG2 cells, and the results of flow cytometry (shown in Figure 4B) were in accordance with the confocal images.

Taken together, these results indicate that the liposomes that contained 4Gal-DTPA-DSPE could effectively target the HepG2 cells via the ASGP-R.

\section{Cell cytotoxicity assay (MTT)}

The cytotoxicity of free DOX and DOX liposomes at various concentrations is shown in Figure 5. We found that the cytotoxicity in HepG2 cells increased with increasing DOX and DOX liposome concentration shown in Figure 5A. Compared with unmodified liposomes, the cellular uptake of Galmodified liposomes was greater because of the Gal-mediated endocytosis process, resulting in a higher cytotoxicity.

The cytotoxicity of free DOX and DOX liposomes in Hela cells is shown in Figure 5B. No significant difference in the cytotoxicity of Hela cells was shown between unmodified and Gal-modified liposomes, because there was no ASGP-R on the surface of Hela cells. Moreover, blank 4Gal-liposomes did not induce a visible cytotoxicity effect, indicating that the 4Gal-DTPA-DSPE possessed good biocompatibility.

\section{Pharmacokinetics of 4Gal-liposomes}

To investigate the pharmacokinetics process in vivo, free DOX, conventional liposomes, and 4Gal-liposomes (10\%) were administrated into three groups of rats. Then blood samples were collected at the designated time points, and DOX concentrations were measured by high-performance liquid chromatography with ultraviolet detection. The plasma clearance curves of free DOX, conventional liposomes, and 4 Gal-liposomes $(10 \%)$ in rats are shown in Figure 6. Clearance of free DOX from the blood circulation was very rapid, and the DOX concentration decreased to $0.18 \mu \mathrm{g} / \mathrm{mL}$ at 4 hours. Compared with free DOX, conventional liposomes and 4Gal-liposomes displayed slower clearance from the circulating system in vivo. The plasma concentrations of DOX in the conventional liposomes and 4Gal-liposomes groups were $0.76 \mu \mathrm{g} / \mathrm{mL}$ and $1.21 \mu \mathrm{g} / \mathrm{mL}$ at 4 hours postinjection, respectively. However, elimination rates in the plasma of the rats treated with $4 \mathrm{Gal}-$ liposomes were even slower than 


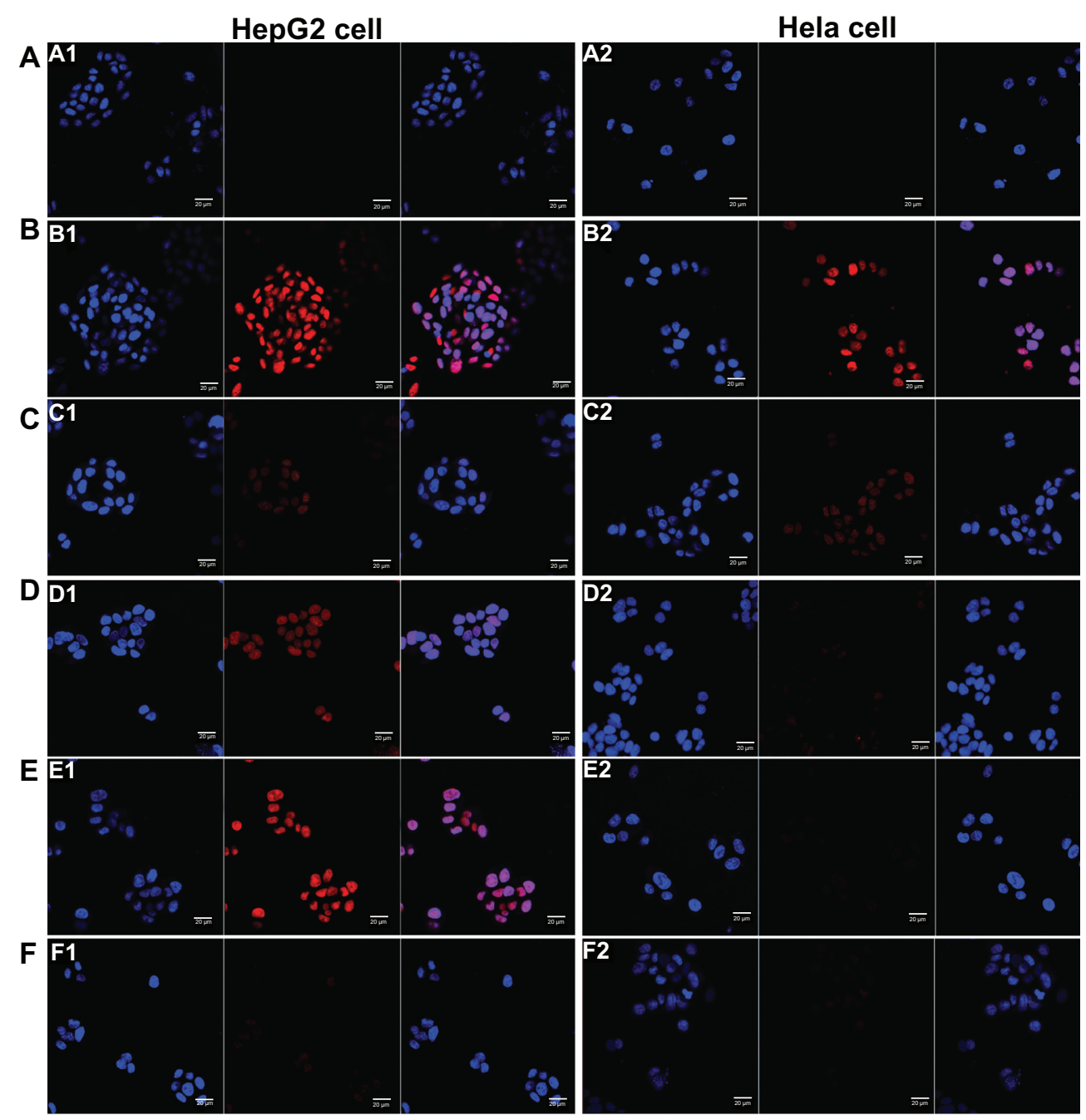

Figure 3 Confocal scanning microscopy images of HepG2 cells (A) and Hela cells (B) incubated with blank medium (AI and A2), free doxorubicin (B I and B2), conventional liposomes (CI and C2), four galactose-modified liposomes (4Gal-liposomes) (5\%) (DI and D2), 4Gal-liposomes (I0\%) (EI and E2), and I00 mM galactose + 4Gal-liposomes (I0\%) (FI and F2) for 2 hours at $37^{\circ} \mathrm{C}$. Cells were fixed and then treated with $4^{\prime}, 6$-diamidino-2-phenylindole for nuclei staining. Red: fluorescence of doxorubicin. Blue: fluorescence of 4',6-diamidino-2-phenylindole. Pink: the merger fluorescence of blue and red.

conventional liposomes. It was assumed that the circulation time of 4Gal-liposomes was prolonged with the high density of hydrophilic Gals on the surface.

The key pharmacokinetic parameters are summarized in Table 2. The elimination half-life of 4Gal-liposomes was increased by 4.9-fold and 2.1-fold in comparison with that of free DOX and conventional liposomes, respectively. In addition, the value of the area under the concentration curve was found to be significantly increased for 4Gal-liposomes.

\section{Tissue distribution in vivo of $4 \mathrm{Gal}-$ liposomes}

To investigate the dynamic biodistribution of 4Gal-liposomes in mice, the fluorescence images of various organs at different time points were recorded by the in vivo imaging system. Representative fluorescence images of mice after administration of free DOX and DOX liposomes are shown in Figure 7. The fluorescence of free DOX quickly decreased in liver (Group B), and the fluorescence was also observed in the heart, spleen, and kidney, which indicated the toxicity of free DOX to other organs. Fluorescence of Group D (4Galliposomes 5\%) and Group E (4Gal-liposomes 10\%) exhibited significantly enhanced accumulation of 4Gal-liposomes in liver in comparison with those injected with conventional liposomes (Group C) at 3 hours and 5 hours, confirming the in vivo targeting ability of 4Gal-liposomes toward liver tissue. We could assume that the fluorescence of 4Gal-liposomes increased after 3 hours because of the high density of aqueous layer on the surface of liposomes, which extended the mean residence time. For conventional liposomes, the fluorescence accumulated in liver might be attributed to the well-known passive effect of targeting. As shown in Group D 


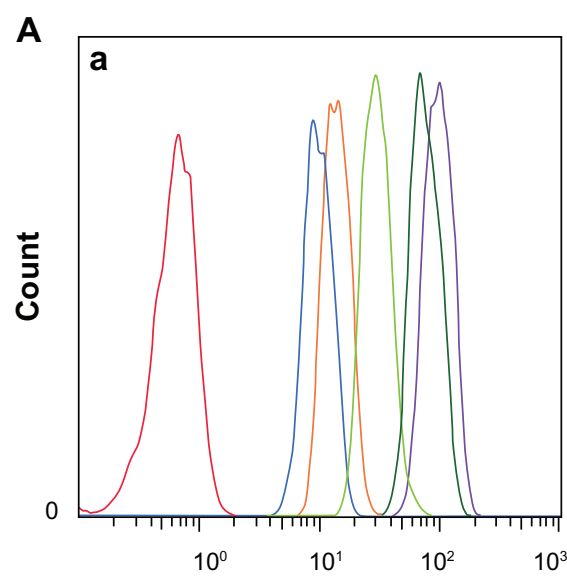

FL2 LOG: FL2 LOG

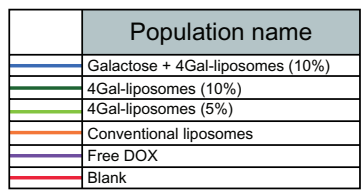

a

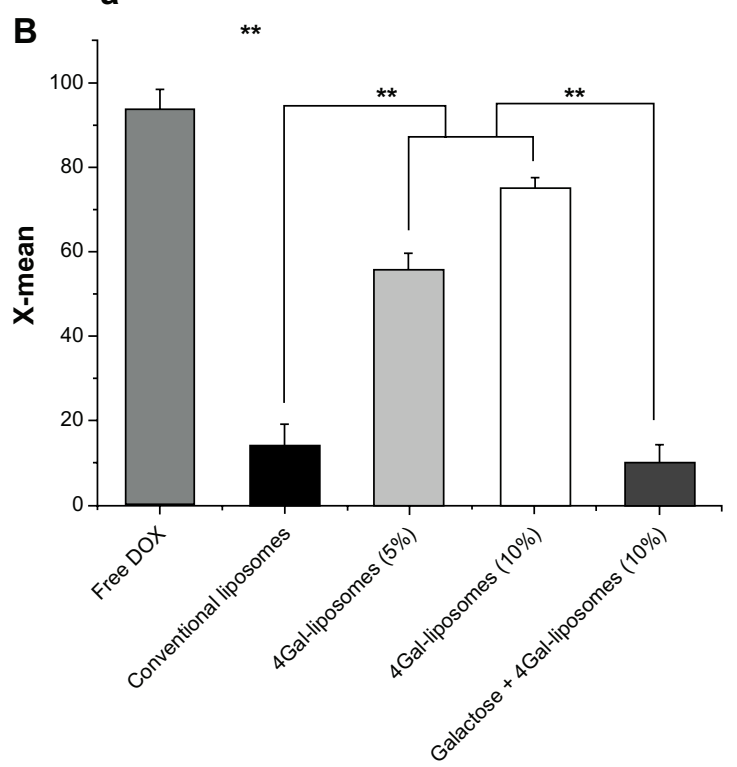

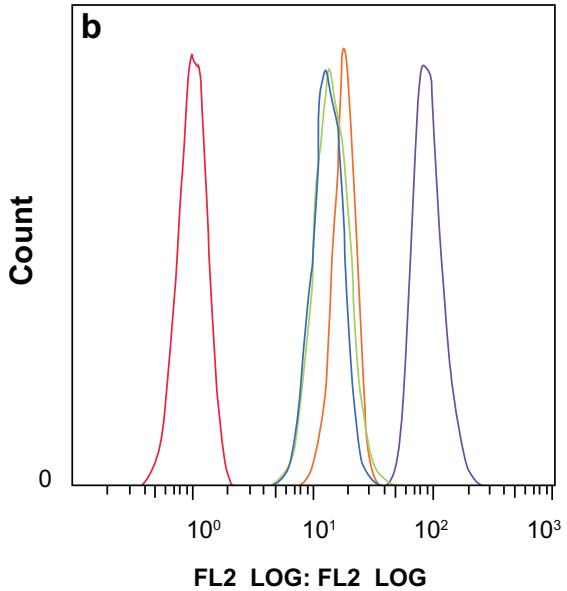

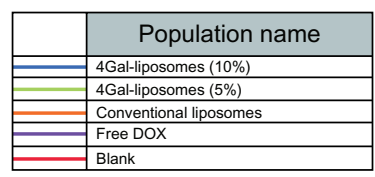

b

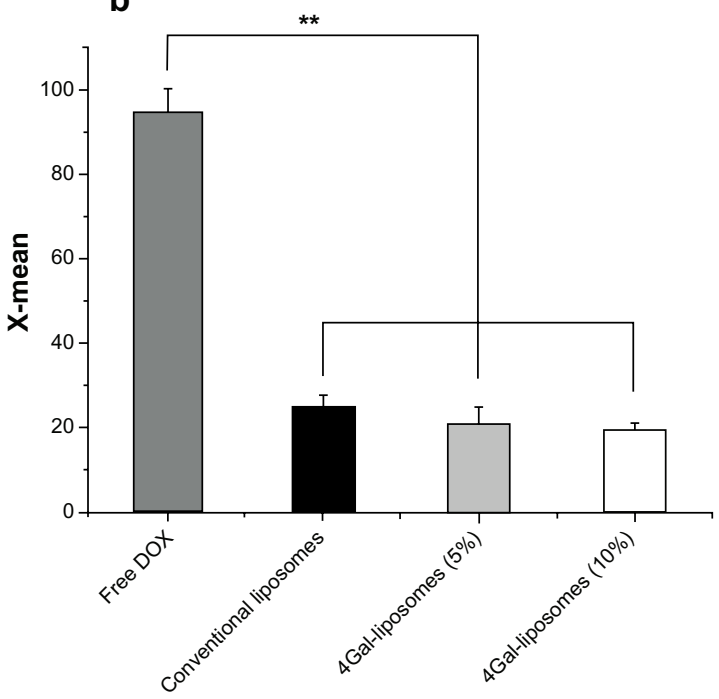

Figure 4 Flow cytometry analysis (A) of HepG2 cells (a) and Hela cells (b) after incubating with free doxorubicin (DOX) and DOX liposomes for 2 hours with $10 \%$ fetal bovine serum medium. The relative fluorescence intensity (B) of free DOX and DOX liposomes in HepG2 cells (a) and Hela cells (b) after incubating with I0\% fetal bovine serum medium for 2 hours using flow cytometry analysis $(\mathrm{n}=3), * * \mathrm{p}<0.05$.

Abbreviation: 4Gal-liposomes, four galactose-modified liposomes.

and Group E, almost no fluorescence was observed in other tissues, indicating few liposomes entering these organs. The organ distributions implied that the liver-targeting ability of DOX might be enhanced by the liver-targeting delivery system of $4 \mathrm{Gal}$-liposomes.

\section{Study on frozen sections of liver}

The analysis of frozen sections of liver was carried out to study the mechanism of the targeting ability of $4 \mathrm{Gal}-$ liposomes to liver tissue. The fluorescence intensity images from DOX are shown in Figure 8. The figure reveals that some labeled nuclei were large and round (presumed hepatocyte) and brightly stained, whereas other nuclei were oblong, oval (presumed nonparenchymal), or, in some cases, indented. ${ }^{33,34}$ Thus, the nonparenchymal cells and hepatocytes could be distinguished by their distinct morphologies, as indicated by the arrow $\rightarrow$ (parenchymal cells) and arrow $\leftarrow$ (nonparenchymal cells). Distribution of relatively strong DOX fluorescence could 

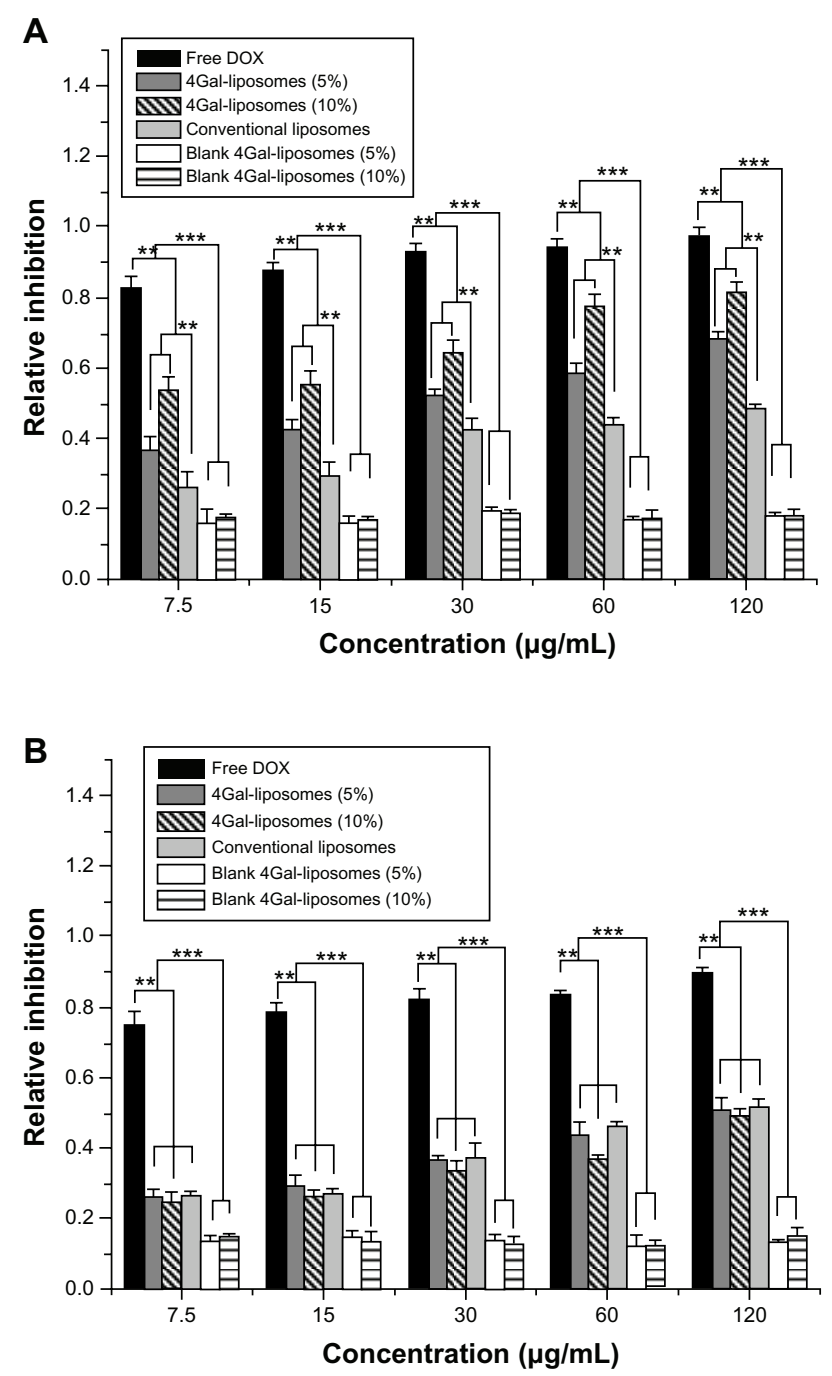

Figure 5 Relative inhibition of free doxorubicin (DOX) and DOX liposomes incubated in HepG2 cells (A) and Hela cells (B) with serum for 24 hours $(n=3)$. $* * P<0.05$, ***P $<0.01$.

Abbreviation: 4Gal-liposomes, four galactose-modified liposomes.

be observed in the hepatocytes treated with Gal-modified liposomes, indicating that the liposomes incorporated with the 4Gal-DTPA-DSPE showed a remarkably specific effect of targeting to the hepatocytes.

\section{Discussion}

\section{Synthesis and characterization of 4Gal-DTPA-DSPE conjugates}

In this study, we focused on the potential ligands with higher affinity than monoantennary galactosides. DSPE as a lipophilic moiety was incorporated into the membrane of liposomes, and the amino group of DSPE was linked to the carboxyl group of DTPA. DTPA was employed to connect DSPE and Gals with its five modifiable carboxyl groups.

In the synthetic process (shown in Figure 1), DTPA was firstly activated by the acetic anhydride to form
DTPA anhydride. The amino group of DSPE was then covalently linked to the free carboxyl group of DTPA anhydride. Coupling the carboxyl group of DTPA anhydride with the amino group of DSPE was performed by mixing a 10 -fold molar excess (a 20-fold equivalent excess) of DTPA anhydride with the DSPE in anhydrous pyridine. The lipid solution should be dropwise added into the vigorously stirred DTPA anhydride solution. In this way, only one hydroxyl group of DTPA participated in the reaction, preventing multisubstituted products. The remaining carboxyl groups could be further coupled to the galactosyl groups. Pyridine was used as a solvent and catalyst. It was important to ensure that the pyridine was absolutely anhydrous, because DTPA anhydride would be hydrolyzed when encountering even a trace amount of water.

The next step was to connect the carboxyl groups of DTPA and 1-hydroxyl group of Gals. Three methods have been studied. Firstly, thionyl chloride $\left(\mathrm{SOCl}_{2}\right)$ was used to activate the carboxyl group of DTPA. However, DSPE was found to be unstable in the strong acidic environment of $\mathrm{SOCl}_{2}$. We presumed that the ester bond of DSPE was unstable under this condition. Secondly, dicyclohexylcarbodiimide was utilized as an activator, and 4-dimethylaminopyridine acted as a catalyst to attach Gals to the carboxyl group of DTPA by covalent binding. However, the target compound still could not be achieved by this strategy. Thirdly, we therefore tried to activate the hydroxyl groups of Gals instead of carboxyl groups of DTPA. Under the optimized phase-transfercatalyzed conditions $\left(\mathrm{K}_{2} \mathrm{CO}_{3}, \mathrm{Bu}_{4} \mathrm{NBr}, \mathrm{CH}_{2} \mathrm{Cl}_{2}-\mathrm{H}_{2} \mathrm{O}\right.$, reflux), DSPE-DTPA was coupled with 2,3,4,6-tetra-O-acetyl- $\beta$-Dgalactopyranosyl bromide, generating the desired product.

The final step was the deacetylation of the hydroxyl groups of galactosides. As two types of ester bonds, namely galactosylated ester bond and lecithin ester bond, should not be hydrolyzed (shown in Figure 1), it was very crucial to selectively break the ester bond of acetyl. Firstly, triethylamine was used to give a base solution to hydrolyze the ester bond of acetyl. However, a side product always existed through thin layer chromatography (TLC) analysis. We believed that in a strong base solution, the glycosidic bond was easily broken, leading to reaction with $\mathrm{CH}_{3} \mathrm{OH}$ to form the side product. Hence, dry gaseous ammonia was used in an ice water bath to form a mild base environment. We found that the reaction temperature had a significant influence on the ratio of the desired product to the side product. When the reaction temperature was $0^{\circ} \mathrm{C}$ approximately (in an ice water bath), the ratio was appropriate. Under these mild conditions, the reaction time was monitored by TLC and we obtained the desired compound. 


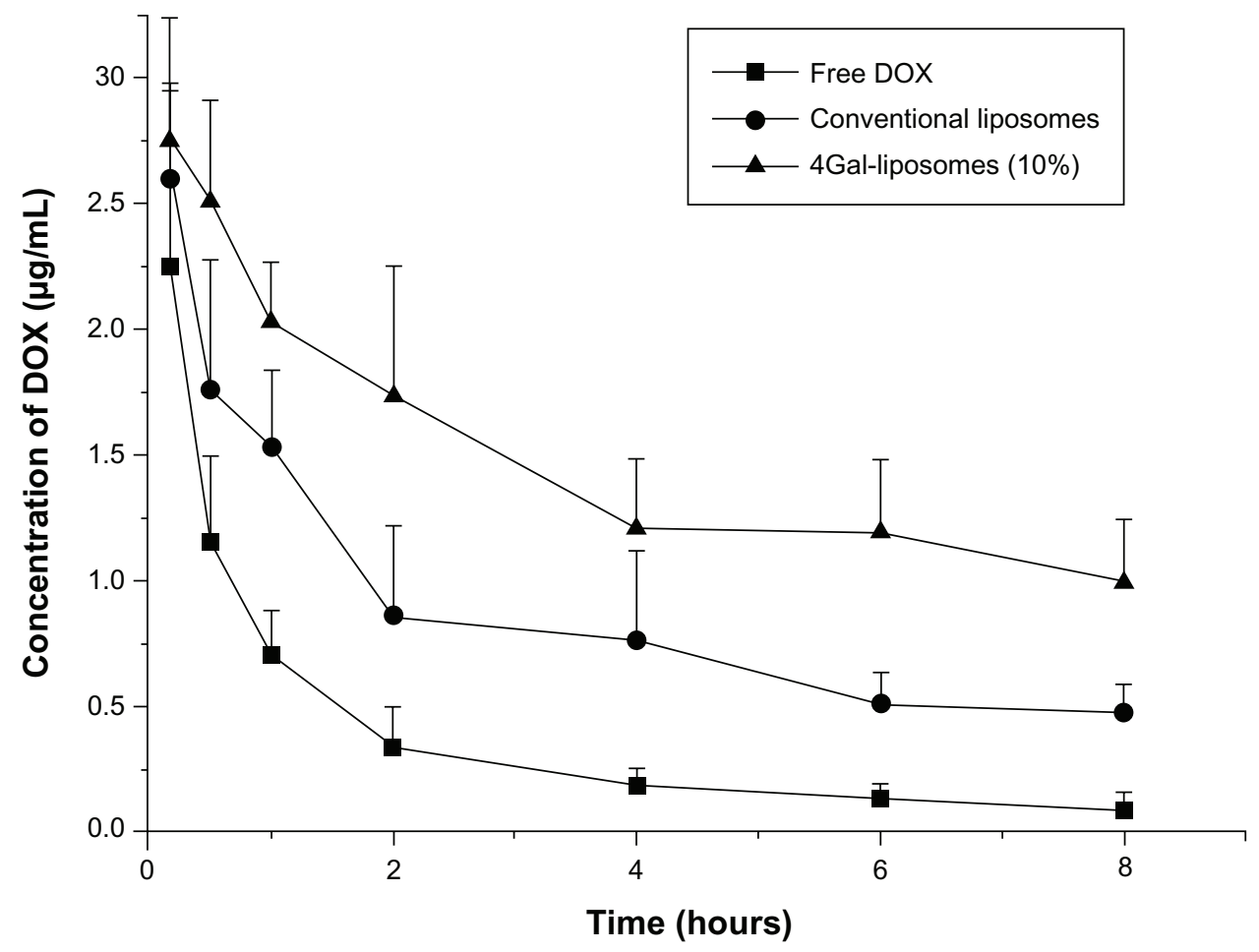

Figure 6 Plasma concentrations of doxorubicin (DOX) in normal mice after intravenous injection of free DOX, conventional liposomes, and four galactose-modified liposomes (4Gal-liposomes) (10\%). All groups were given a DOX equivalent dose of $10 \mathrm{mg} / \mathrm{kg}$.

\section{The surface hydration modification of $4 \mathrm{Gal}-$ liposomes}

Surface modification has been achieved by incorporating hydrophilic moieties, such as polyethylene glycol (PEG), which were chemically conjugated to lipids in order to reduce immune recognition and rapid clearance. ${ }^{35}$ The surface of the liposomal membrane was modified with dendritic hydrophilic Gals to reduce aggregation and avoid recognition by the reticuloendothelial system (RES). This strategy was similar to liposome PEGylation and is often referred to as surface hydration modification. In this work, four galactose were conjugated to the carboxyl groups of DTPA, which were linked to the terminal amino group of DSPE. This led to the presence of hydrophilic groups on the surface of the liposomal membrane, and a dense aqueous layer might be formed around the liposomes by interaction between the dendritic hydrophilic hydroxyl groups of Gals and water molecules, thus avoiding the RES uptake and prolonging circulation time.

\section{Intracellular uptake of liposomes}

DOX is a potent anticancer drug that is known to readily intercalate into DNA strands, ${ }^{36}$ and many studies have shown that DOX preferentially accumulates into the nuclear compartment of cells. ${ }^{37,38}$ Free DOX is mainly located in the nucleus and shows the most intense intracellular fluorescence (shown in Figure A1 and B1) as the positive control in vitro, attributed to its direct and rapid partition into the membrane

Table 2 DOX pharmacokinetics (mean \pm SD) in plasma after intravenous injection of free DOX, conventional liposomes and 4Galliposomes (10\%)

\begin{tabular}{llccc}
\hline Parameter & Unit & Free DOX & Conventional liposomes & 4Gal-liposomes (I 0\%) \\
\hline $\mathrm{V}(\mathrm{c})$ & $\mathrm{mL}$ & $810.39 \pm 324.50$ & $830.85 \pm 141.33$ & $844.63 \pm 143.28$ \\
$\mathrm{~T} \mathrm{I} / 2 \alpha$ & $\mathrm{h}$ & $0.29 \pm 0.03$ & $0.45 \pm 0.1 \mathrm{I}$ & $0.90 \pm 0.21$ \\
$\mathrm{~T} \mathrm{I} / 2 \beta$ & $\mathrm{h}$ & $2.91 \pm 0.83$ & $6.67 \pm 6.75$ & $14.26 \pm 4.95$ \\
$\mathrm{AUC}$ & $(\mu \mathrm{g} / \mathrm{mL}) * \mathrm{~h}$ & $3.22 \pm 1.14$ & $11.28 \pm 0.47$ & $32.38 \pm 2.93$ \\
$\mathrm{CL}(\mathrm{s})$ & $\mathrm{mL} / \mathrm{h}$ & $777.28 \pm 426.50$ & $221.58 \pm 6.67$ & $77.20 \pm 5.81$ \\
\hline
\end{tabular}

Note: $(\mathrm{n}=3)$

Abbreviations: c, center compartment; s, systemic; h, hour; $\mathrm{V}$, apparent volume of distribution; $\mathrm{T} \mathrm{I} / 2 \alpha$, the half-life of the distribution phase; $\mathrm{T} \quad \mathrm{I} / 2 \beta$, elimination half-life; $\mathrm{AUC}$, area under concentration-time curve; $\mathrm{CL}$, clearance. 
without release from liposomes and its highly nucleophilic nature. ${ }^{39}$ However, free DOX presents serious cardiotoxicity, which limits clinical application. ${ }^{40}$ The administration of DOX in liposome-encapsulated form has been advocated as a means of changing the distribution of DOX in vivo and reducing the cardiac damage induced by DOX ${ }^{41-44}$ Preclinical experiments with liposome-encapsulated DOX indicate that this form of delivery may be effective in decreasing the cardiotoxic effect of the drug. In addition, drastic changes in the clinical pharmacokinetics of DOX have been observed using liposomal delivery. ${ }^{45,46}$ Currently, PEGylated liposomal DOX (Doxil ${ }^{\circledR}$; Janssen Products, LP, Horsham, PA, USA) is a US Food and Drug Administration-approved marketed DOX formulation. ${ }^{47,48}$ However, liposomal DOX is less effective than free DOX. ${ }^{49,50}$ Therefore, our study aimed to develop a Gal-modified liposomal formulation for DOX delivery in order to reduce its cardiotoxicity and enhance its effect of targeting to hepatocyte by ASGP-R-mediated endocytosis.

To demonstrate the specific cell binding and internalization of 4Gal-liposomes, ASGP-R-positive HepG2 cells were chosen as target cells, whereas ASGP-R-negative Hela cells were applied as negative cells. The confocal microscopy images and flow cytometry data demonstrated that 4Galliposomes resulted in significantly higher cell association by ASGP-R-positive HepG2 cells compared with the negative control. But similar cellular behavior was found with the two liposomal formulations when they were incubated in ASGP-R-negative Hela cells. In the competition study, the HepG2 cells' association of 4Gal-liposomes was suppressed to a lower level by the presence of excess free Gal, whereas no significant changes were found in Hela cells. All these phenomena suggest that 4Gal-liposomes could enhance specific cell binding and cellular uptake in HepG2 cells due to the mediating of Gal, and depending on the ASGP-R expression level on the cell surface as well.

\section{Liposome uptake by liver in vivo}

As hepatocytes represent most hepatic cells and liver diseases mainly develop from hepatocytes, it was very important to confirm that the drugs were not only concentrated in nonparenchymal cells but also internalized by hepatocytes. The frozen sections of liver that stained green (the cell membrane), blue (the nuclei of the cells), and red (the DOX) could distinguish the hepatocytes from nonparenchymal cells. Figures 7 and 8 show that there was significant difference of distribution among free DOX and liposomal formulations, and Gal-modified liposomes

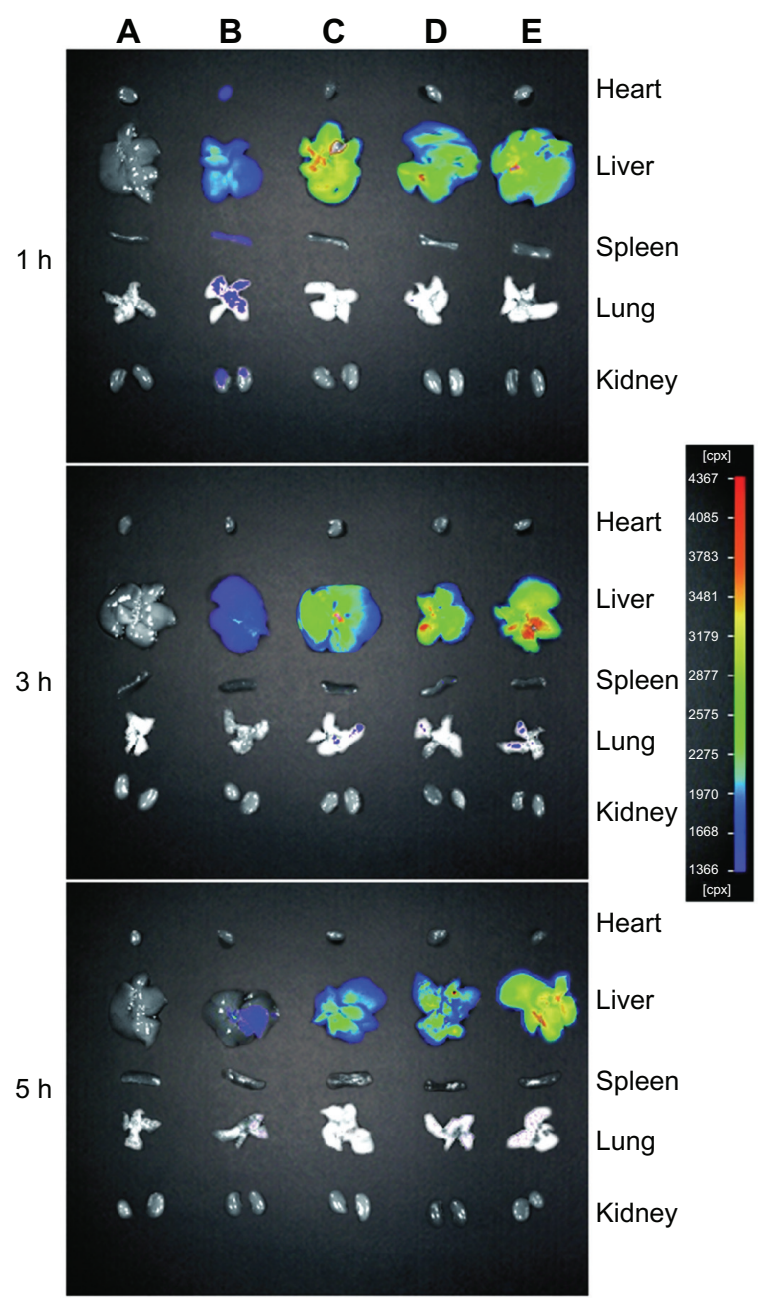

Figure 7 The fluorescence images of various organs of Kunming mice sacrificed at I hour (h), 3 hours, and 5 hours after injection with phosphate-buffered saline (A), free doxorubicin (B), conventional liposomes (C), four galactose-modified liposomes (5\%) (D), and four galactose-modified liposomes (I0\%) (E) in vivo imaging system.

showed a remarkably specific effect of targeting to the liver tissue after 3 hours.

The pharmacokinetic experiments and biodistribution studies revealed that the inclusion of 4Gal-DTPA-DSPE in the liposomal bilayer extended systemic circulation. There was a general consensus that serum proteins adsorbed on to the surface of conventional liposomes could mediate recognition of the liposomes by macrophages of the RES, and facilitate clearance of liposomes from the circulation. Coating liposomes with 4Gal-DTPA-DSPE decreased the blood clearance considerably, most likely due to reduced protein adsorption and liposome aggregation. We assumed that with 4Gal-DTPA-DSPE modification of the liposomal surface, a dense aqueous layer was formed around the liposomes, thus avoiding the attraction of opsonins. As a result, 4Gal-liposomes that escaped trapping by the cells of the RES 

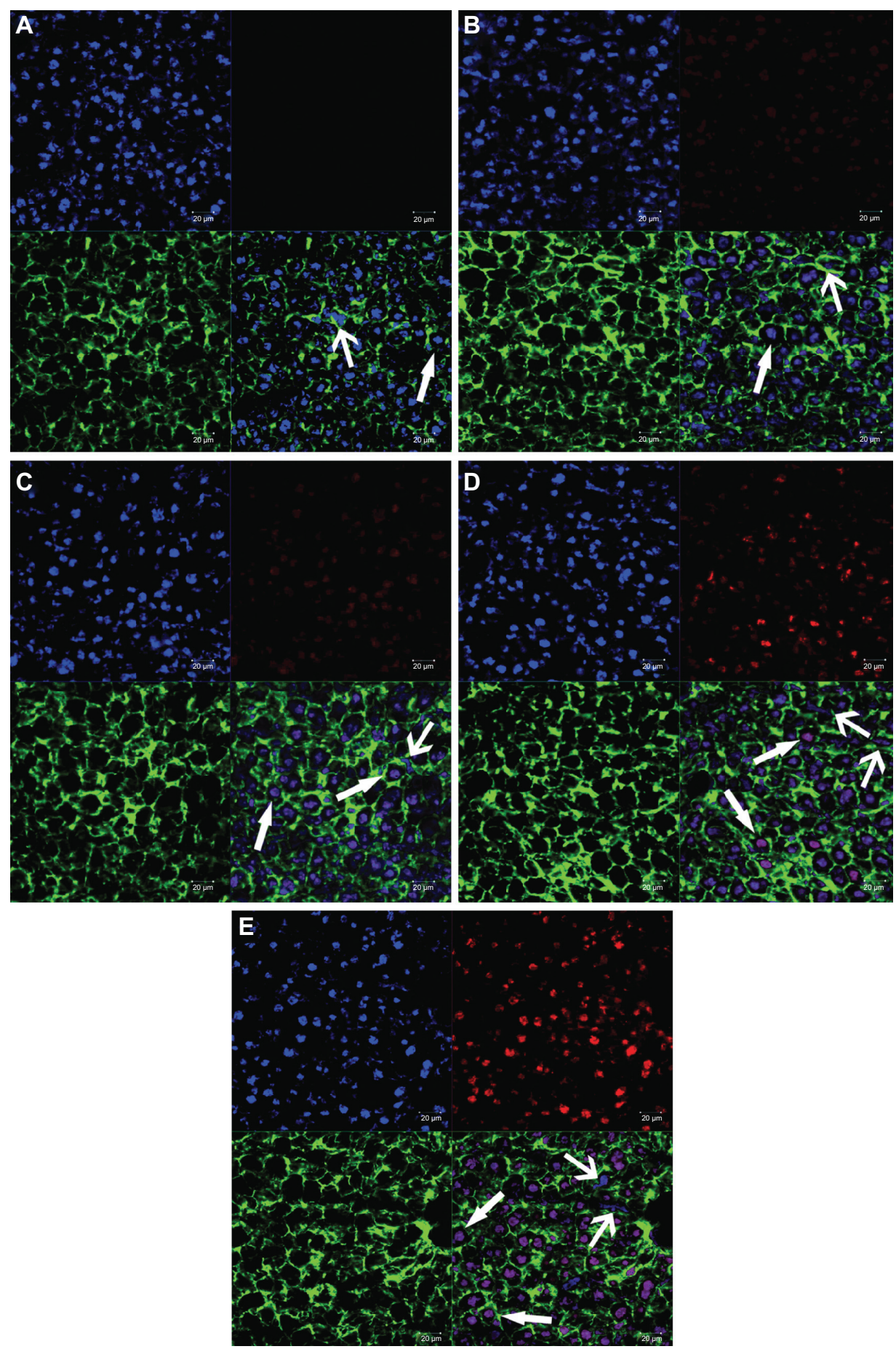

Figure 8 Confocal scanning microscopy images of liver sections of free doxorubicin (DOX) and DOX liposomes, blank (A), free DOX (B), conventional liposomes (C), four galactose-modified liposomes (5\%) (D), and four galactose-modified liposomes (10\%) (E). Nuclei were stained blue with 4',6-diamidino-2-phenylindole, fluorescein isothiocyanate was shown as green fluorescence, DOX was shown as red fluorescence, and the merger image is on the bottom right.

Notes: Arrows with triangle head point to hepatocytes, and the others point to non-parenchymal cells.

had a prolonged circulation time and accumulated in the liver by active targeting.

\section{Conclusion}

In the present study, a hepatocyte-targeting drug delivery system was successfully constructed by incorporating synthetic 4Gal-DTPA-DSPE ( $5 \%$ and $10 \%, \mathrm{~mol} / \mathrm{mol}$ ) into liposomes, where Gal was used for active targeting to the liver and applying for prolonged circulation. DOX, as a drug model, was effectively encapsulated into the liposomes. The cellular uptake and cell cytotoxicity tests indicated that $4 \mathrm{Gal}-$ liposomes had a significant targeting function toward human 
hepatoma cells and could deliver DOX into HepG2 cells effectively. Furthermore, the results of pharmacokinetic and biodistribution experiments provided evidence that 4Gal-liposomes possessed an enhanced plasma half-life and higher liver accumulation in vivo. Finally, the study of frozen sections of liver confirmed that the drugs were internalized by hepatocytes rather than concentrated in nonparenchymal cells. These results suggest that liposomes containing 4GalDTPA-DSPE could be a potential drug carrier system for hepatocyte-selective targeting.

\section{Future direction}

The purpose of this study was to investigate whether content delivery of DOX could be targeted to the normal liver. The next step of this study is to explore the targeted delivery characteristics of this formulation in liver tumors of animal models.

\section{Acknowledgments}

This work was supported by the National Natural Science Foundation of China (Grant No 81173003/h3008).

\section{Disclosure}

The authors report no conflicts of interest in this work.

\section{References}

1. Li L, Wang H, Ong ZY, et al. Polymer-and lipid-based nanoparticle therapeutics for the treatment of liver diseases. Nano Today. 2010;5(4): 296-312.

2. Wang $\mathrm{S}, \mathrm{Xu} \mathrm{H}, \mathrm{Xu} \mathrm{J}$, et al. Sustained liver targeting and improved antiproliferative effect of doxorubicin liposomes modified with galactosylated lipid and PEG-Lipid. AAPS PharmSciTech. 2010;11(2):870-877.

3. Smith JS, Xu Z, Byrnes AP. A quantitative assay for measuring clearance of adenovirus vectors by Kupffer cells. J Virol Methods. 2008;147(1):54-60.

4. Stockert RJ. The asialoglycoprotein receptor: relationships between structure, function, and expression. Physiol Rev. 1995;75(3):591-609.

5. Poelstra K, Prakash J, Beljaars L. Drug targeting to the diseased liver. J Control Release. 2012;161(2):188-197.

6. Spiess M. The asialoglycoprotein receptor: a model for endocytic transport receptors. Biochemistry. 1990;29(43):10009-10018.

7. Geffen I, Spiess M. Asialoglycoprotein receptor. Int Rev Cytol B. 1992;137:181-219.

8. Baenziger J, Maynard Y. Human hepatic lectin. Physiochemical properties and specificity. J Biol Chem. 1980;255(10):4607-4613.

9. Baenziger J, Fiete D. Galactose and N-acetylgalactosamine-specific endocytosis of glycopeptides by isolated rat hepatocytes. Cell. 1980;22(2 Pt 2):611-620.

10. Lee YC, Townsend RR, Hardy MR, et al. Binding of synthetic oligosaccharides to the hepatic Gal/GalNAc lectin. Dependence on fine structural features. J Biol Chem. 1983;258(1):199-202.

11. Sato A, Takagi M, Shimamoto A, Kawakami S, Hashida M. Small interfering RNA delivery to the liver by intravenous administration of galactosylated cationic liposomes in mice. Biomaterials. 2007;28(7): 1434-1442.

12. Mandal A, Das S, Basu M, Chakrabarti R, Das N. Hepatoprotective activity of liposomal flavonoid against arsenite-induced liver fibrosis. J Pharmacol Exp Ther. 2007;320(3):994-1001.
13. Managit C, Kawakami S, Yamashita F, Hashida M. Effect of galactose density on asialoglycoprotein receptor-mediated uptake of galactosylated liposomes. J Pharm Sci. 2005;94(10):2266-2275.

14. Murao A, Nishikawa M, Managit C, et al. Targeting efficiency of galactosylated liposomes to hepatocytes in vivo: effect of lipid composition. Pharm Res. 2002;19(12):1808-1814.

15. Mammen M, Choi SK, Whitesides GM. Polyvalente Wechselwirkungen in biologischen Systemen: Auswirkungen auf das Design und die Verwendung multivalenter Liganden und Inhibitoren. [Polyvalent interactions in biological systems: implications for the design and use of multivalent ligands and inhibitors] Angewandte Chemie. 1999;110(20):2908-2953. German.

16. Kawakami S, Munakata C, Fumoto S, Yamashita F, Hashida M. Targeted delivery of prostaglandin E1 to hepatocytes using galactosylated liposomes. J Drug Target. 2000;8(3):137-142.

17. Grant CWM, Karlik S, Florio E. A liposomal MRI contrast agent: phosphatidylethanolamine-DTPA. Magn Reson Med. 1989;11(2): 236-243.

18. Ishiwata H, Vertut-Doï A, Hirose T, Miyajima K. Physical-chemistry characteristics and biodistribution of poly(ethylene glycol)-coated liposomes using poly(oxyethylene) cholesteryl ether. Chem Pharm Bull. (Tokyo). 1995;43(6):1005-1011.

19. Yeagle PL. Cholesterol and the cell membrane. Biochimica et Biophysica Acta. 1985;822(3-4):267-287.

20. Gleason MM, Medow MS, Tulenko TN. Excess membrane cholesterol alters calcium movements, cytosolic calcium levels, and membrane fluidity in arterial smooth muscle cells. Circ Res. 1991;69(1): 216-227.

21. Kirby C, Clarke J, Gregoriadis G. Effect of the cholesterol content of small unilamellar liposomes on their stability in vivo and in vitro. Biochem J. 1980;186(2):591-598.

22. Khorev O, Stokmaier D, Schwardt O, Cutting B, Ernst B. Trivalent, $\mathrm{Gal} / \mathrm{GalNAc}$-containing ligands designed for the asialoglycoprotein receptor. Biorg Med Chem. 2008;16(9):5216-5231.

23. Feng L, Zhang L, Yan Z, Gu B, Wang C, LuW. Experimental study on liposomal drug delivery system for lymphatic targeting. Acta Biophysica Sinica. 2010;26:735-749.

24. Zhu S, Li Y, Yu B. Synthesis of betavulgaroside III, a representative triterpene seco-glycoside. J Org Chem. 2008;73(13):4978-4985.

25. Zhao H, Li X, Liu H, Li Y, Wu C. Synthesis and characterization of ferrocenylmethylaminobenzoic acids and their glucosyl esters. Synth React Inorg Met Org Chem. 2000;30(3):473-483.

26. Park IY, Kim TH, Kim YK, Choi YJ, Nah JW, Cho CS. Galactosylated chitosan/carbonate apatite nanohybridization for cell specificity and high transfection efficiency as a DNA carrier. Key Eng Mater. 2007;342: 437-440.

27. Park I-K, Jiang H-L, Cook S-E, et al. Galactosylated chitosan (GC)-graftpoly (vinyl pyrrolidone)(PVP) as hepatocyte-targeting DNA carrier: in vitro transfection. Arch Pharm Res. 2004;27(12): 1284-1289.

28. Zhang X-Q, Wang X-L, Zhang P-C, et al. Galactosylated ternary DNA/ polyphosphoramidate nanoparticles mediate high gene transfection efficiency in hepatocytes. J Control Release. 2005;102(3):749.

29. Jere D, Jiang H, Arote R, et al. Degradable polyethylenimines as DNA and small interfering RNA carriers. Expert Opin Drug Deliv. 2009;6(8): $827-834$.

30. Park I, Kim T, Kim S, et al. Visualization of transfection of hepatocytes by galactosylated chitosan-graft-poly (ethylene glycol)/DNA complexes by confocal laser scanning microscopy. Int J Pharm. 2003;257(1): 103-110.

31. Jiang H-L, Kwon J-T, Kim E-M, et al. Galactosylated poly (ethylene glycol)-chitosan-graft-polyethylenimine as a gene carrier for hepatocytetargeting. J Control Release. 2008;131(2):150-157.

32. Díez S, Miguéliz I, De Ilarduya CT. Targeted cationic poly (D, L-lacticco-glycolic acid) nanoparticles for gene delivery to cultured cells. Cell Mol Biol Lett. 2009;14(2):347-362.

33. Longmuir KJ, Haynes SM, Baratta JL, Kasabwalla N, Robertson RT. Liposomal delivery of doxorubicin to hepatocytes in vivo by targeting heparan sulfate. Int J Pharm. 2009;382(1):222-233. 
34. Baratta JL, Ngo A, Lopez B, Kasabwalla N, Longmuir KJ, Robertson RT. Cellular organization of normal mouse liver: a histological, quantitative immunocytochemical, and fine structural analysis. Histochem Cell Biol. 2009;131(6):713-726.

35. Lian T, Ho RJY. Trends and developments in liposome drug delivery systems. J Pharm Sci. 2001;90(6):667-680.

36. Gabbay E, Grier D, Fingerle R, et al. Interaction specificity of the anthracyclines with deoxyribonucleic acid. Biochemistry. 1976;15(10): 2062.

37. Coley H, Amos W, Twentyman P, Workman P. Examination by laser scanning confocal fluorescence imaging microscopy of the subcellular localisation of anthracyclines in parent and multidrug resistant cell lines. Br J Cancer. 1993;67(6):1316.

38. Marquardt D, Center MS. Drug transport mechanisms in HL60 cells isolated for resistance to adriamycin: evidence for nuclear drug accumulation and redistribution in resistant cells. Cancer Res. 1992;52(11): 3157-3163.

39. Düzgüneş N, Nir S. Mechanisms and kinetics of liposome-cell interactions. Adv Drug Del Rev. 1999;40(1):3-18.

40. Liu X, Chua CC, Gao J, et al. Pifithrin- $\alpha$ protects against doxorubicininduced apoptosis and acute cardiotoxicity in mice. Science Signaling. 2004;286(3):H933.

41. Gabizon AA. Selective tumor localization and improved therapeutic index of anthracyclines encapsulated in long-circulating liposomes. Cancer Res. 1992;52(4):891-896.

42. Gabizon A, Isacson R, Libson E, et al. Clinical studies of liposomeencapsulated doxorubicin. Acta Oncol. 1994;33(7):779-786.
43. Gabizon A, Meshorer A, Barenholz Y. Comparative long-term study of the toxicities of free and liposome-associated doxorubicin in mice after intravenous administration. J Natl Cancer Inst. 1986;77(2): 459-469.

44. Park JW. Liposome-based drug delivery in breast cancer treatment. Breast Cancer Res. 2002;4(3):95.

45. Gabizon AA. Liposomal anthracyclines. Hematol Oncol Clin North Am. 1994;8(2):431.

46. Olson F, Mayhew E, Maslow D, Rustum Y, Szoka F. Characterization, toxicity and therapeutic efficacy of adriamycin encapsulated in liposomes. Eur J Cancer Clin Oncol. 1982;18(2):167-176.

47. Chen ZG. Small-molecule delivery by nanoparticles for anticancer therapy. Trends Mol Med. 2010;16(12):594-602.

48. Wang R, Billone PS, Mullett WM. Nanomedicine in action: an overview of cancer nanomedicine on the market and in clinical trials. J Nanomater. 2013. doi:10.1155/2013/629681.

49. Chandaroy P, Sen A, Alexandridis P, Hui SW. Utilizing temperaturesensitive association of Pluronic F-127 with lipid bilayers to control liposome-cell adhesion. Biochimica et Biophysica Acta. 2002;1559(1): $32-42$.

50. Xiang Y, Liang L, Wang X, Wang J, Zhang X, Zhang Q. Chloride channel-mediated brain glioma targeting of chlorotoxin-modified doxorubicine-loaded liposomes. J Control Release. 2011;152(3): $402-410$. 


\section{Supplementary materials Synthesis of 4Gal-DTPA-DSPE conjugates} Synthesis of DTPA anhydride (I)

Diethylenetriaminepentaacetic acid (DTPA) (19.75 g, $0.05 \mathrm{~mol})$ and acetic anhydride $(37.8 \mathrm{~mL}, 0.4 \mathrm{~mol})$ were added to anhydrous pyridine $(25 \mathrm{~mL})$, and the mixture was stirred for 24 hours at $65^{\circ} \mathrm{C} \pm 5^{\circ} \mathrm{C}$. Then the mixture was filtered and the solid was washed with acetic anhydride $(20 \mathrm{~mL})$ and anhydrous ether $(20 \mathrm{~mL})$ three times, respectively, and the solvent was removed in a vacuum. Compound (1) was obtained as a white powder ( $87 \%$ yield). Proton nuclear magnetic resonance ( $\left.{ }^{1} \mathrm{H}-\mathrm{NMR}\right)(400 \mathrm{MHz}$, dimethyl sulfoxide), $\delta /$ ppm: $3.71(\mathrm{~s}, 8 \mathrm{H}), 3.31(\mathrm{~s}, 2 \mathrm{H}), 2.75(\mathrm{t}, 4 \mathrm{H})$, $2.60(\mathrm{t}, 4 \mathrm{H})$.

\section{Synthesis of DSPE-DTPA (2)}

DTPA anhydride (5 g, $13.99 \mathrm{mmol})$ was added to anhydrous pyridine $(100 \mathrm{~mL})$. The mixture was heated until the lipid was dissolved to give a clear solution. In a separate flask, distearoylphosphatidylethanolamine (DSPE) (1 g, $1.34 \mathrm{mmol})$ was warmed with anhydrous pyridine $(100 \mathrm{~mL})$ until dissolved. The lipid solution was added to the vigorously stirred DTPA anhydride solution. After addition, the solution was heated to reflux for 70 minutes, during which time an orange tint appeared but the solution remained clear. $\mathrm{H}_{2} \mathrm{O}(50 \mathrm{~mL})$ was then added to the reaction mixture, and refluxing was continued for 70 minutes to hydrolyze remaining anhydride linkages. The mixture was cooled to room temperature and rotary evaporated to dryness. The residue was purified by column chromatography on a silica gel eluted with $\mathrm{CHCl}_{3}: \mathrm{CH}_{3} \mathrm{OH}: \mathrm{H}_{2} \mathrm{O}$ : formic acid $(65: 25: 4: 1)$. Compound (2) was obtained as a yellow powder ( $48 \%$ yield). ${ }^{1} \mathrm{H}-\mathrm{NMR}\left(400 \mathrm{MHz}_{\mathrm{CDCl}}\right.$ ), $\delta / \mathrm{ppm}: 5.15$ (s, 2H), 4.36 $(\mathrm{d}, 1 \mathrm{H}), 4.09$ (d, 3H), $3.95(\mathrm{~s}, 2 \mathrm{H}), 3.70(\mathrm{~s}, 8 \mathrm{H}), 3.44(\mathrm{~s}, 2 \mathrm{H})$, $3.29(\mathrm{~s}, 2 \mathrm{H}), 2.73(\mathrm{t}, 4 \mathrm{H}), 2.58(\mathrm{t}, 4 \mathrm{H}), 2.12(\mathrm{t}, 3 \mathrm{H}), 1.61$ $(\mathrm{s}, 8 \mathrm{H}), 1.27(\mathrm{~s}, 52 \mathrm{H}), 0.89$ (t, 6H). MS (ESI+) m/z: $[\mathrm{M}+\mathrm{H}]^{+}$ calcd for $\mathrm{C}_{55} \mathrm{H}_{103} \mathrm{~N}_{4} \mathrm{O}_{17} \mathrm{P}[\mathrm{M}+\mathrm{H}]^{+} 1123.4$, found 1123.90 .
Synthesis of 4-Ac-galactose-DTPA-DSPE (3)

$\mathrm{K}_{2} \mathrm{CO}_{3}$ (199 mg, 1.2 equivalent), $\mathrm{H}_{2} \mathrm{O}(11.7 \mathrm{~mL})$, and $\mathrm{Bu}_{4} \mathrm{NBr}$ (38.7 mg, 0.1 equiv) were added to a solution of DSPE-DTPA (333.6 mg, $0.3 \mathrm{mmol}$ ) and 2,3,4,6-tetraO-acetyl- $\beta$-D-galactopyranosyl bromide $(639.6 \mathrm{mg}, 5.2$ equiv) in $\mathrm{CH}_{2} \mathrm{Cl}_{2}(18 \mathrm{~mL})$. The resulting mixture was refluxed for 6 hours at $40^{\circ} \mathrm{C}$ and was then diluted with $\mathrm{CH}_{2} \mathrm{Cl}_{2}(36 \mathrm{~mL})$. The organic phase, after being washed with water and brine, respectively, was dried over $\mathrm{Na}_{2} \mathrm{SO}_{4}$ and then concentrated in a vacuum. The residue was purified by column chromatography on a silica gel eluted with $\mathrm{CHCl}_{3}: \mathrm{CH}_{3} \mathrm{OH}$ (9:1). Compound (3) was obtained as yellow oil (59\% yield). ${ }^{1} \mathrm{H}-\mathrm{NMR}\left(400 \mathrm{MHz} \mathrm{CDCl}_{3}\right), \delta / \mathrm{ppm}$ : $6.15(\mathrm{~d}, 4 \mathrm{H}), 5.52(\mathrm{~d}, 4 \mathrm{H}), 5.41(\mathrm{t}, 4 \mathrm{H}), 5.07(\mathrm{t}, 4 \mathrm{H}), 4.83$ $(\mathrm{t}, 1 \mathrm{H}), 4.75(\mathrm{t}, 3 \mathrm{H}), 4.49(\mathrm{t}, 4 \mathrm{H}), 4.16(\mathrm{~s}, 8 \mathrm{H}), 3.70(\mathrm{~s}, 8 \mathrm{H})$, $3.30(\mathrm{~s}, 2 \mathrm{H}), 2.74(\mathrm{t}, 4 \mathrm{H}), 2.59(\mathrm{t}, 4 \mathrm{H}), 2.15(\mathrm{~s}, 12 \mathrm{H}), 2.11$ $(\mathrm{s}, 13 \mathrm{H}), 2.06(\mathrm{~s}, 12 \mathrm{H}), 2.01(\mathrm{~s}, 12 \mathrm{H}), 1.60(\mathrm{~s}, 7 \mathrm{H}), 1.28$ $(\mathrm{s}, 55 \mathrm{H}), 0.88(\mathrm{t}, 6 \mathrm{H})$. MS (ESI+) $\mathrm{m} / \mathrm{z}:[\mathrm{M}+\mathrm{H}]^{+}$calcd for $\mathrm{C}_{111} \mathrm{H}_{175} \mathrm{~N}_{4} \mathrm{O}_{53} \mathrm{P}[\mathrm{M}+\mathrm{H}]^{+} 2444.55$, found 2444.13.

\section{Synthesis of 4Gal-DTPA-DSPE (4)}

Compound (3) (253 mg, $0.1 \mathrm{mmol}$ ) was dissolved in a mixture of anhydrous $\mathrm{CHCl}_{3}(3 \mathrm{~mL})$ and anhydrous $\mathrm{CH}_{3} \mathrm{OH}$ $(8 \mathrm{~mL})$. Then the mixture was stirred for 5 minutes to form a homogenous phase, and dry gaseous ammonia was introduced for 1 hour into the flask, which was kept in an ice-salt bath. Next, the solution was stirred in an ice water bath for 3-4 hours (the reaction time was determined by TLC). After removal of the solvent, sticky yellow oil was recovered. The oil was purified by column chromatography on a silica gel eluted with $\mathrm{CHCl}_{3}: \mathrm{CH}_{3} \mathrm{OH}(2: 1)$. Compound (4) was obtained as yellow oil (63\% yield). ${ }^{1} \mathrm{H}-\mathrm{NMR}\left(400 \mathrm{MHz} \mathrm{CDCl}_{3}\right)$,

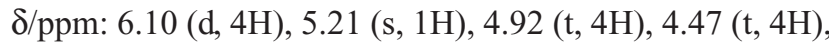
$4.41(\mathrm{~d}, 4 \mathrm{H}), 4.22(\mathrm{~d}, 8 \mathrm{H}), 3.70(\mathrm{~s}, 8 \mathrm{H}), 3.29$ (s, 2H), 2.75 (t, 4H), 2.60 (t, 4H), 2.31 (d, 4H), $1.88(\mathrm{~s}, 6 \mathrm{H}), 1.58(\mathrm{~s}, 4 \mathrm{H})$, $1.26(\mathrm{~s}, 53 \mathrm{H}), 0.88(\mathrm{t}, 6 \mathrm{H}) . \mathrm{MS}\left(\mathrm{ESI}^{+}\right) \mathrm{m} / \mathrm{z}:[\mathrm{M}+\mathrm{H}]^{+}$calcd for $\mathrm{C}_{79} \mathrm{H}_{143} \mathrm{~N}_{4} \mathrm{O}_{37} \mathrm{P}[\mathrm{M}+\mathrm{H}]^{+} 1770.92$, found 1770.94 . 


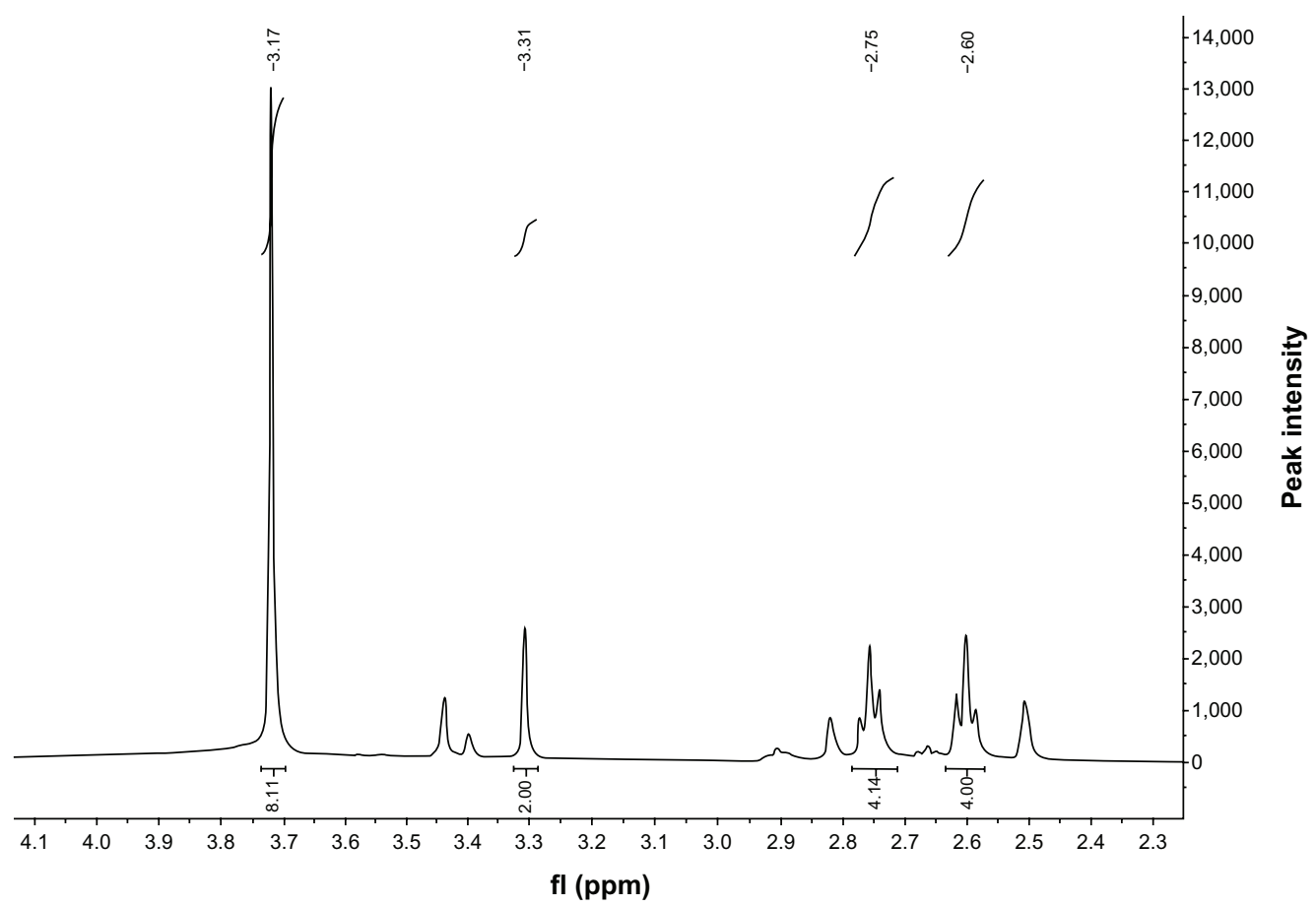

Figure SI Proton nuclear magnetic resonance $(400 \mathrm{MHz})$ spectrum of diethylenetriaminepentaacetic acid anhydride.

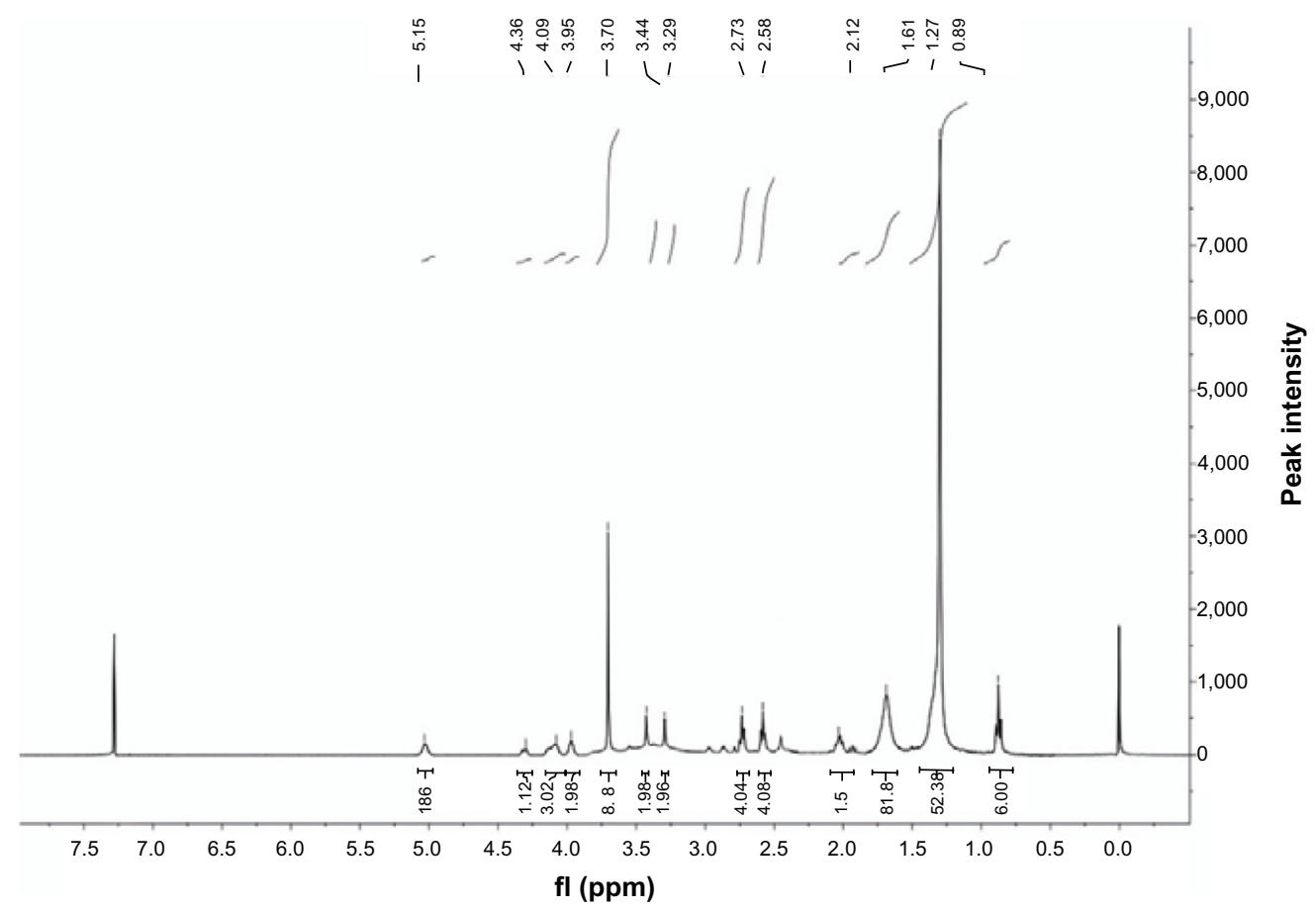

Figure S2 Proton nuclear magnetic resonance $(400 \mathrm{MHz})$ spectrum of diethylenetriaminepentaacetic acid-distearoylphosphatidylethanolamine. 


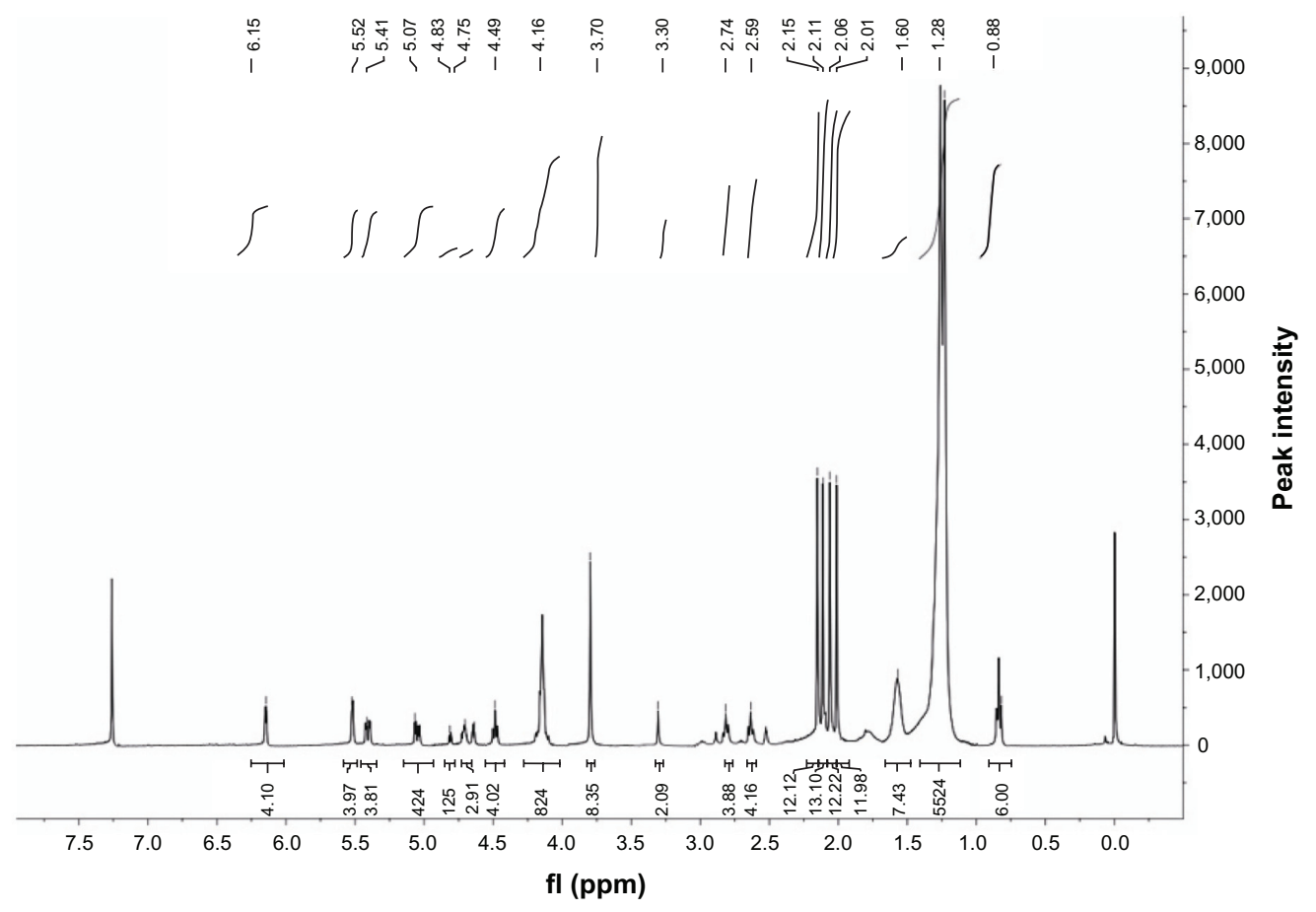

Figure S3 Proton nuclear magnetic resonance $(400 \mathrm{MHz})$ spectrum of tetravalent galactosylated diethylenetriaminepentaacetic acid-distearoylphosphatidylethanolamine. 
A

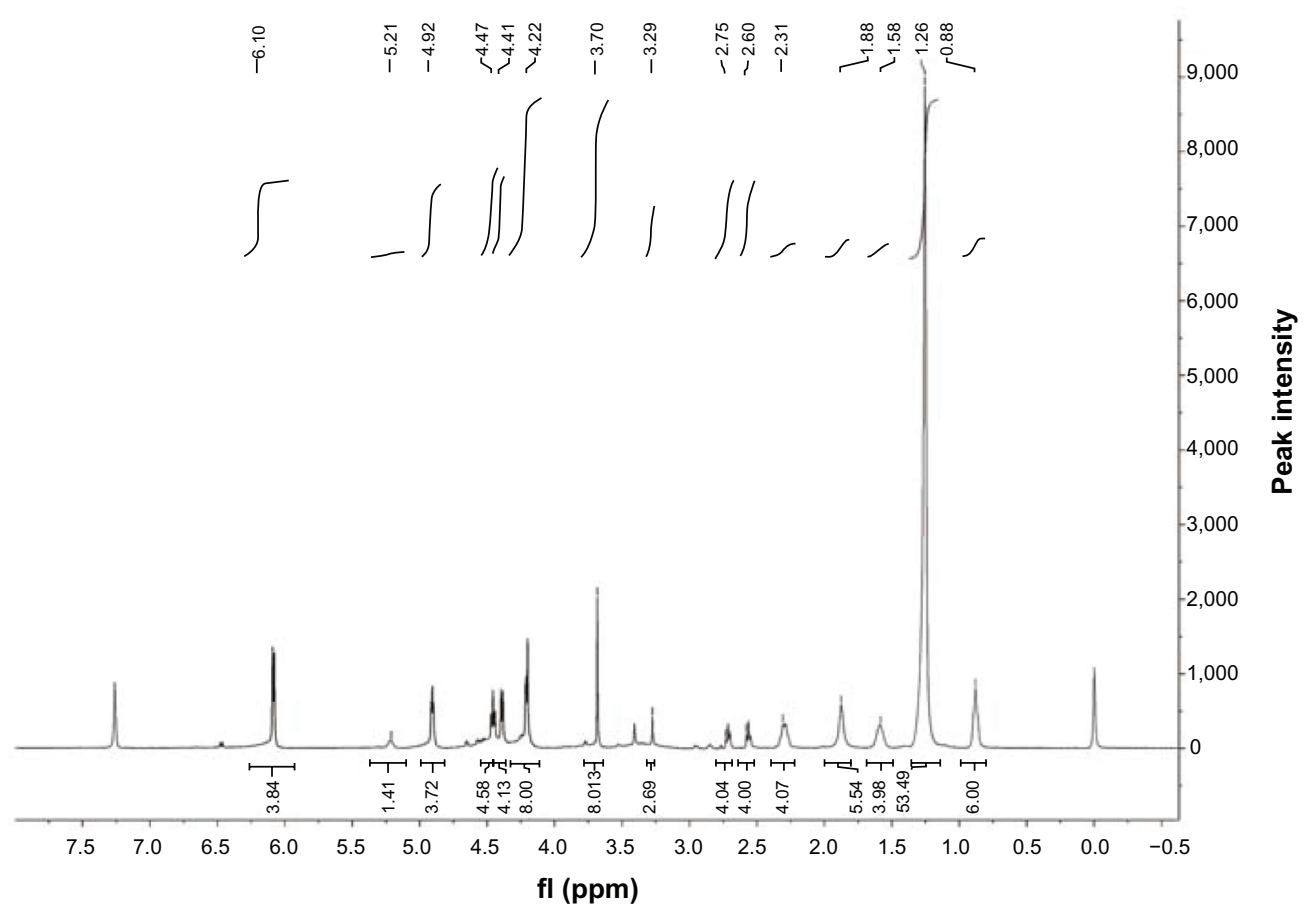

B

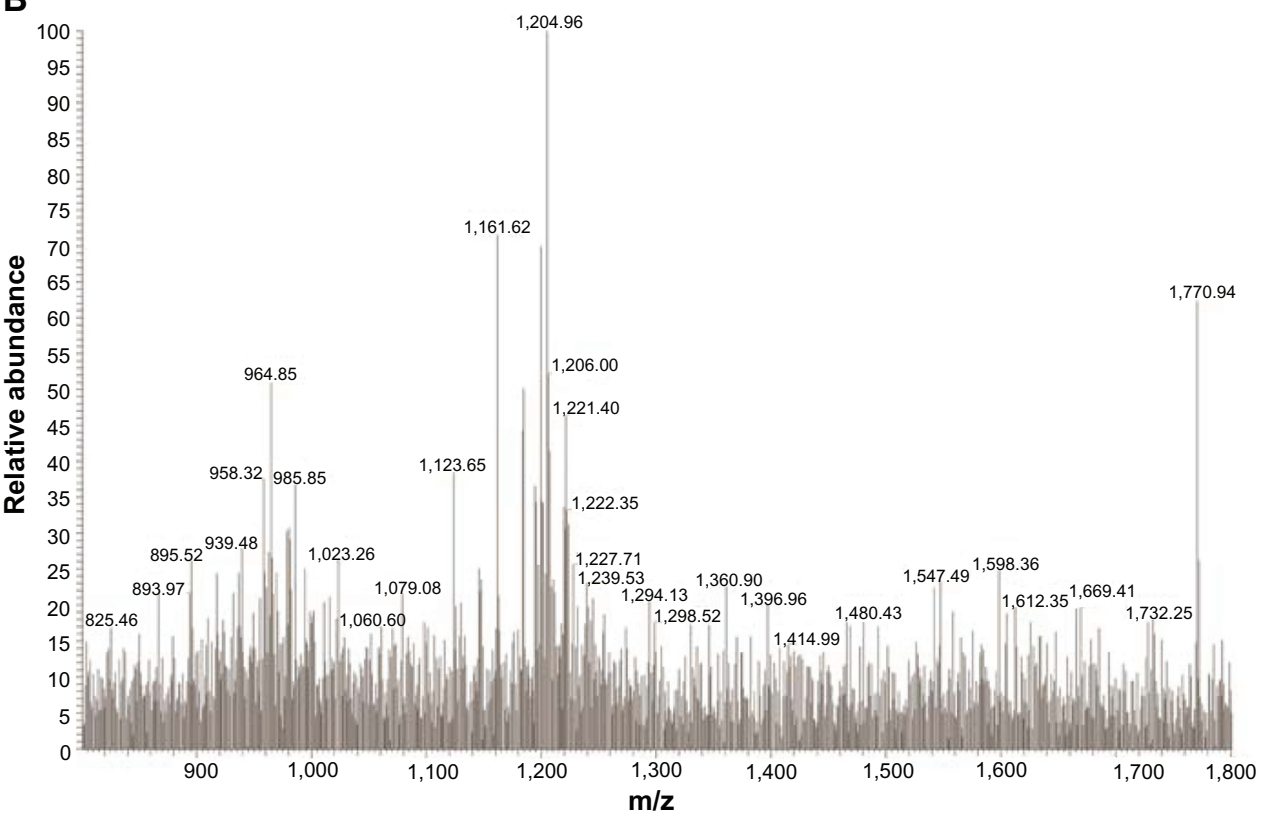

Figure S4 Proton nuclear magnetic resonance $(400 \mathrm{MHz})$ spectrum (A) and mass spectrum (B) of galactosylated diethylenetriaminepentaacetic aciddistearoylphosphatidylethanolamine.

International Journal of Nanomedicine

Dovepress

\section{Publish your work in this journal}

The International Journal of Nanomedicine is an international, peerreviewed journal focusing on the application of nanotechnology in diagnostics, therapeutics, and drug delivery systems throughout the biomedical field. This journal is indexed on PubMed Central, MedLine, CAS, SciSearch $\AA$, Current Contents $\AA /$ Clinical Medicine,
Journal Citation Reports/Science Edition, EMBase, Scopus and the Elsevier Bibliographic databases. The manuscript management system is completely online and includes a very quick and fair peer-review system, which is all easy to use. Visit http://www.dovepress.com/ testimonials.php to read real quotes from published authors. 